\title{
Experiencias paradiplomáticas en la región de Tarapacá y su proyección subregional
}

\author{
Paradiplomatic experiences in the Tarapaca region \\ and its subregional projection
}

\author{
Gilberto Aranda \\ Cristian Ovando \\ Alejandro Corder
}

\section{Resumen}

La paradiplomacia se constituye en una categoría que da cuenta de nuevas aristas de la realidad internacional de América Latina en esta última década. Siguiendo una tendencia consolidada en varias latitudes del mundo, esta apunta a la emergencia de actores subnacionales, surgidos de regiones y comunas, de sectores específicos de la administración del Estado y de actores privados interesados en el desarrollo de sus comunidades, que intentan con relativa eficacia internacionalizarse y encontrar un lugar activo en la globalización. Esta realidad se hace patente en las «regiones ganadoras» de nuestro país, especialmente en regiones como Tarapacá que, por su vocación internacional histórica, se ha insertado progresiva y exitosamente en el concierto internacional, especialmente con las regiones de los países que forman parte de la subregión andina,

Artículo resultado del proyecto de investigación Cátedra Andrés Bello: Experiencias paradiplomáticas en la Región de Tarapacá. Convenio Andrés Bello. Este proyecto contó con la colaboración en el trabajo de campo de Alejandro Salinas y del equipo conformado por Emilio Ugarte, Carla Julio y María Daniela Fortín. <garanda@uchile.cl>; <a_corder@ hotmail.com>.

Recibido el 9 de septiembre de 2009, aceptado 16 de diciembre 2009. 
pese a la existencia de algunas limitaciones institucionales y de contexto. Caracterizar estas experiencias presentes en la región de Tarapacá, según la discusión teórica y aportes de fuentes primarias es el objetivo de este artículo.

PAlabras Clave: Paradiplomacia - relaciones transfronterizas - Tarapacá - triple frontera andina.

\section{Abstract}

Paradiplomacy is a new category in theories on international reality that has become apparent in Latin America over the last decade. Following a trend that has consolidated in various parts of the world, it points to the emergence of subnational actors in regions and communes, specific areas of public administration and private actors interested in developing their communities, which pursue both an effective internationalization as well as finding an active role in globalization. This new reality is apparent in «winning regions» of our country, such as Tarapaca which, owing to its historical international calling and in spite of institutional and contextual limitations, have gradually and successfully inserted themselves in the international scenario, especially in the Andean subregion.

KEY WORDS: paradiplomacy - cross-border relations - Tarapaca - Andean triple frontier. 
Gilberto Aranda et al. • Experiencias paradiplomáticas en la región de Tarapacá...

\section{INTRODUCCIÓN}

La categoría paradiplomacia constituye una herramienta conceptual que se ha posicionado con fuerza en el ámbito de las relaciones internacionales en los últimos 20 años Los trabajos de Jean Der Derian (1987), Panatonis Soldatos (1990), Francisco Aldecoa y Michael Keating (2000), entre otros, aparecen como los principales referentes en la reflexión en torno a las actividades internacionales que han implementado las regiones de distintos países bajo el alero de la política exterior de sus gobiernos centrales y a veces de manera independiente e incluso contradiciendo dicha política.

La experiencia de regiones como Quebec en Canadá, o el País Vasco en España constituyen referentes de la forma en que las regiones han asumido el desafío de diseñar y concretar empresas internacionales, tanto en términos de cooperación transfronteriza como a través del establecimiento de vínculos transnacionales a partir de una serie de actores subnacionales.

Como toda categoría de las ciencias sociales, el concepto de paradiplomacia está expuesto a problemas de definición y generalización. El alargamiento de los conceptos surge de lo heterogéneo que son los casos estudiados en base a estas categorías nuevas (Sartori, 1995). Por ello, sostenemos que la paradiplomacia, al constituirse como una categoría clave para aproximarnos a la realidad latinoamericana y particularmente a algunas regiones chilenas con vocación internacional, como es el caso de las «regiones ganadoras» del Norte Grande (Amhilat- Szary, 1997), nos demanda tener en cuenta su adecuada intención y extensión conceptual (Sartori, 1995). Pues, conjeturamos que sus notas distintivas, que nos permiten establecer sus significados posibles y atributos, están suficientemente desarrolladas, pero su extensión, es decir, el conjunto de casos de referencia, especialmente los casos de este lado del mundo, si bien han empezado a estudiarse, el tratamiento conceptual no ha sido lo suficientemente cotejado, trayendo como consecuencia cierta imprecisión y distorsión de lo que realmente se quiere estudiar con este neologismo.

Junto con tratar de precisar el concepto de paradiplomacia, intentaremos analizar los procesos y actores que intervienen en actividades paradiplomáticas desde estas regiones.

Una de las razones para ello es que aquellos no siguen la lógica tradicional de la diplomacia que caracteriza a estos tres países En este sentido, la identificación de dichas dinámicas está fuertemente condicionada por la particularidad que tienen las relaciones transfronterizas que se han configurado entre las regiones de Tarapacá y la reciente región de Arica y Parinacota y sus pares de Perú y Bolivia.

Conocida es la serie de desencuentros que se han sucedido entre los Estados de Chile y sus dos vecinos. Por un lado con Bolivia durante los últimos 15 años a partir de la re-emergencia de su demanda marítima y con el Perú, 
en los últimos dos años, desencuentros que han surgido con este último país a partir de la presentación de la demanda marítima al Tribunal de la Haya (2009) que cuestiona los límites marítimos con Chile. En tanto, la lógica de las relaciones transfronterizas presentes en esta triple frontera, que conjeturamos puede sustraerse de estos embates diplomáticos, adquiere varias particularidades que resulta importante tener en cuenta a la hora de analizar los actores. Entre ellos se destacan un intercambio comercial histórico entre localidades de la subregión, que se proyecta hasta hoy; la participación de estas localidades en la cooperación internacional para el desarrollo que le significa percibir importantes recursos través de estas gestiones; la vigencia de intercambios culturales de variada índole entre ellas, la emergencia de procesos migratorios transfronterizos que conllevan la respuesta de diversos actores de estas regiones, entre otros.

\section{EL CONTEXTO INTERNACIONAL EN QUE SURGE LA PARADIPLOMACIA}

Una vez finalizada la Guerra Fría los analistas internacionales se han cuestionado constantemente sobre el cambio cultural, social, político y económico ocurrido en el sistema mundial. En efecto, desde la segunda mitad del siglo XX las relaciones transnacionales han comenzado a tomar un giro algo distinto y considerablemente más abierto.
Roberto Russell señalaba que el fin del juego bipolar entre las dos grandes potencias del norte de seguro revelaba y explicaba en buena medida los cambios profundos del orden mundial (Russell, 1996; 17). El mismo autor mencionaba que la Guerra Fría había tenido un efecto de "corrimiento de velo", puesto que su dinámica en cuanto a la rivalidad Este/Oeste ocultaba el real significado de las transformaciones. ¿Cuáles eran esas transformaciones? ¿Qué es lo que estaba cambiando en las relaciones internacionales?

Si echamos un vistazo al mundo actual nos damos cuenta de que este es diametralmente diferente al de principios del Siglo XX, donde la idea de Estado-nación llegaba a manifestarse de manera más clara y concurrente con la realidad. Así es como se constata que en las relaciones internacionales y en el ámbito de su disciplina era precisamente el Estado el actor internacional primordial en la política mundial.

Desde la perspectiva realista, -teoría política que se centra principalmente en la naturaleza y características del Estado como actor internacionalsolo el Estado-nación debía ser considerado actor internacional puesto que la sociedad transnacional era una sociedad de Estados y las relaciones por tanto estaban constituidas por interacciones exclusivamente entre ellos (Gallardo, 2006: 21). Para esta corriente, la política internacional consistía básicamente en la lucha por el poder. A juicio de Morgenthau, entre los factores que constituían dicho poder de los 
Estados sobresalía la diplomacia, a la que definía «como verdadero cerebro del poder nacional en la medida que le daba dirección, peso y el aliento de un poder real» (Morgenthau, 1986: 177).

En ese sentido, la actividad diplomática no podía ser desarrollada o implementada por entidades distintas de las estatales.

Más aún, el papel que el Estado tenía durante esos años era la de copar o colmar todas las actividades que abarcaban su territorio, las concernientes a los recursos naturales, la capacidad industrial, la fuerza militar, la población, la moral nacional, la calidad del gobierno y particularmente la calidad de la diplomacia (Morgenthau, 1986; 143-189), de manera que se hacía responsable del cúmulo de actividades que la sociedad en su totalidad articulaba en un espacio y territorio concretos. Esto en la medida de lo posible.

El Estado era un actor central, particularmente en América Latina. Alain Rouquie señalaba que «el Estado constituía una de las especificidades del perfil sociopolítico de las naciones latinoamericanas» (Rouquie, 1987; 125). Esto debido a que en estos países, al igual que en los de Europa, el Estado, como unidad principal, se dispuso como actor esencial en el desarrollo de las naciones y en la promoción de la satisfacción de las necesidades básicas.

No obstante, a partir de la crisis de los años ochenta, al Estado ya no se le exige que promueva la industrialización (crecimiento hacia adentro) sino que, principalmente, que asegure el modelo económico neoliberal imperante. En ese contexto, el rol de los gobiernos nacionales cambia significativamente, tanto en el plano económico como en el político ${ }^{1}, \mathrm{y}$ «estamos, por tanto, en presencia de procesos de cambio histórico cuya magnitud y calado están afectando no sólo las dinámicas, sino también las estructuras profundas de la economía política mundial moderna» (Ferrero, 2006: 3). A este respecto, se ha identificado un fenómeno complejo, la globalización, por sus profundos efectos a nivel de actores, estructuras y dinámicas.

En lo esencial, entendemos la globalización como un proceso multidimensional de largo aliento y de carácter mundial, que «se refiere literalmente al límite de la integración internacional entendido como un creciente número de economías nacionales mutuamente interconectadas a través del intercambio de bienes, servicios y factores de producción» (Vargas, 2004). Por ello, más que tratarse de un solo fenómeno, se trata de múltiples fenómenos ligados entre sí por el perfil internacional de sus manifestaciones.

1 En efecto, en el ámbito político europeo desde la década de 1980 se comienza a discutir el concepto de subsidiariedad. «De concepto separador de las esferas de lo privado y lo público, pasó a ser el punto de inflexión entre el poder central y el poder regional. En esencia se trata del mismo concepto, es decir, de la limitación relativa del ejercicio del poder de las macrocomunidades, a favor de las comunidades intermedias» (Tapia, 2003). 
La globalización se refleja, particularmente, en un vertiginoso avance del comercio y en una intensa unificación de los mercados locales en un gran y único sistema mundial provocado por el desmantelamiento de las barreras nacionales. En esa dinámica, los gobiernos mundializan sus estrategias y políticas y compiten por el acaparamiento de las inversiones en los mercados globalizados. No obstante, pierden gradualmente su influencia sobre los sujetos de la sociedad globalizada: las empresas y la sociedad civil toman autónomamente sus decisiones de inversión en un sistema social, político y económico globalmente ampliado. En respuesta a ello, plantea Jorge Tapia, se «...ha forzado la puesta en marcha de un proceso de reestructuración y modernización del Estado, que en parte principal se expresa en los procesos de descentralización, regionalización y autonomización territorial relativa, que se extiende incluso, al campo de las relaciones con el exterior» (Tapia, 2003b: 25).

Aparejado a estas tendencias, dos son básicamente los fenómenos que la globalización ha concebido. Uno que responde a flujos externos y otro que responde a flujos internos. Los primeros se refieren al desarrollo de regímenes internacionales; mientras que los segundos aluden a la tendencia a la descentralización ${ }^{2}$ política y adminis-

2 Según James Scott la descentralización se entiende u opera como una reorganización entre las distintas escalas espaciales, de forma que se asiste a un parcial descentra- trativa (de Marsillo, 2006). Existe, en otras palabras, un doble movimiento: por un lado la globalización y, por el otro la transferencia, descentralización o localización -glocalización. ${ }^{3}$ (Swyngedouw, 1992).

Estamos por tanto, según Ferrero, en presencia de procesos de cambio histórico cuya magnitud afecta al Estado y lo modifica en su organización y funcionamiento, pues de modo especial, la disminución de la participación del gobierno central ha implicado que de tal forma, hacia la década de los años noventa el Estado se encuentre en una etapa de reducción y de constante y persistente retirada (Couffignal 2002: 35-51).

El sistema global abandona el concepto de relaciones internacionales basadas exclusivamente en relaciones interestatales, para pasar a una interdependencia compleja entre distintos actores (Keohane y Nye, 1988). El Estado- nación, por tanto, pasa a constituir solo una parte de un sistema mayor.

Consecuentemente, «los gobiernos subnacionales han estado alcanzando

miento del espacio económico nacional al tiempo que la geografía económica mundial se reconfigura en base a un mosaico global de economías regionales subnacionales (Scott, 1988).

3 Se torna pertinente visualizar la globalización como glocalización, entendiendo por tal fenómeno la «incrustación local de lo global de tal modo, que lejos de representar la negación del territorio, estas actividades se materializan en lugares físicos, muy concretos, situados en los territorios nacionales». (Ferrero, 2006: 4) 
un protagonismo nuevo y mayor para la integración social y productiva de las fuerzas locales en las dinámicas globales»(Rhi-Sausi, 2008).

\section{Hacia NUEVAS ESCALAS DE ACCIÓN INTERNACIONAL: LA} EMERGENCIA DE LAS RELACIONES TRANSFRONTERIZAS

Como se dijo, el sistema internacional actual, marcado por la unificación de los mercados locales, el desmantelamiento de las barreras nacionales y la búsqueda de estrategias de adecuación estatal hacia estas demandas, conlleva una serie de interrelaciones transnacionales y transfronterizas que responden a esta complejidad. Uno de los fenómenos relevantes derivados de este proceso es la constante adecuación de las escalas nacionales de actuación a las presiones regionales y globales. Bob Jessop señala que en respuesta a estas presiones, "encontramos que nuevos lugares están emergiendo, nuevos espacios se están creando, nuevas escalas de organización están siendo desarrolladas y están concibiendo acción» (Jessop, 2004: 89). En respuesta a este desafío están surgiendo una serie de estrategias, entre las cuales destacan la formación de regiones transfronterizas y la construcción de redes de ciudades globales (Keating, 2000; Jessop, 2004).

Así visto, el nuevo panorama mundial, una de las maneras de abordar una nueva categoría de acción internacional descentralizada pasaría por redefinir el espacio que la contiene; teniendo en cuenta "que los lugares, espacios y escalas no son predeterminados, sino que son sujetos a luchas discursivas sobre mapeo y denominación» (Jessop, 2004: 27) En este punto destacamos la relevancia de la emergencia de nuevos actores internacionales, como los paradiplomáticos, pues son ellos los encargados de legitimar estos nuevos espacios de actuación.

Particularmente para el caso chileno, se trató de consolidar la inserción a través de «fortalecer capacidades para el desarrollo nacional en el marco de la globalización, desde una América Latina democrática, estable y cohesionada socialmente» (Díaz, 2004). Fortalecimiento que inevitablemente requirió reorientar las políticas de desarrollo y, por añadidura, de cierto reconocimiento a la existencia de actores internacionales subnacionales ${ }^{4}$. Cuestión que en América Latina estaría ocurriendo a través de iniciativas y prerrogativas concretas

4 En efecto, desde el año 2003 existe una unidad dentro de la cancillería, la DICORE, que coordina la acción exterior de las regiones. La Dirección de Coordinación Regional es responsable de apoyar y coordinar a las regiones y municipios del Chile en la realización de sus proyectos e iniciativas en el ámbito internacional. Para ello, DICORE permite vincular a los gobiernos regionales y locales con las direcciones del Ministerio de Relaciones Exteriores y la red de Embajadas, Misiones y Consulados.

Mas información sobre la DICORE, en: http://www.minrel.gov.cl/prontus_minrel/ $\mathrm{s}$ i t e / a r t i c/200800903/ pags/20080903111314.php\#T0 
hacia estos nuevos actores; Vicente Torrijos, señala al respecto: «...la toma de decisiones en materia de relaciones internacionales, tradicionalmente en manos de muy pocas personas, sobre todo en regímenes políticos de corte presidencialista y unitario [como es el caso chileno], irá difuminándose y de hecho, así está sucediendo, en un entramado de cada vez más amplios, complejo y participativo, de consejos consultivos, conferencias sectoriales, comisiones asesoras, comités intersectoriales, etc.» (Torrijos, 2000: 25).

Por otro lado, la evidencia nos dice que las fronteras pierden su significado cuando los actores locales interactúan de forma interdependiente entre ellas, dando cuenta de la existencia de regiones transfronterizas 5 . Las fronteras tienen una influencia más limitada sobre el acondicionamiento del espacio, cuando las diferentes regiones de una y de otra parte de la frontera presentan grandes similitudes en términos geográficos, culturales, y económicos. Se habla entonces de integración natural. Así, en el caso del Norte Grande de Chile, nuestro caso de estudio, en las localidades fronterizas del mundo andino, la identidad se (re)

\footnotetext{
Se define como la interacción entre regiones fronterizas que son «el resultado de la comprobación empírica de que el éxito de una región al interior de su país no es una variable dependiente, automática y mecánicamente de los planes nacionales hechos por el poder central (...), sino consecuencia de la combinación concreta de individuos, instituciones y cultura de esa región en agrupación con otras a ambos lados de las fronteras» (Tapia, 2003: 119).
}

construye gracias a la densidad cultural presente en las localidades que la comprenden. «Ello ocurre generalmente cuando esas localidades son parte de regiones naturales supranacionales, donde los lazos familiares, históricos y culturales prevalecen por sobre los político-administrativos» (González, 2006: 26-27), como es el caso del tripartito.

\section{Definiendo la Paradiplomacia}

Discutidos algunos de los procesos que posibilitan la emergencia de los actores paradiplomaticos y el contexto en que se revitalizan las fronteras como espacios de contacto, a continuación nos abocaremos a su definición.

Entendemos como paradiplomacia «la participación de los gobiernos no centrales en las relaciones internacionales, a través del establecimiento de contactos permanentes o ad hoc con entidades públicas o privadas extranjeras con el propósito de promover diversos aspectos socioeconómicos o culturales, así como cualquier otra dimensión exterior de sus propias competencias constitucionales» (Cornago Prieto 2000: 56$)^{6}$.

6 Entre otras definiciones de paradiplomacia, Jorge Tapia Valdés la define como: el conjunto de actividades, de coordinación, alianza y cooperación para las relaciones económicas y el desarrollo, realizadas por gobiernos subnacionales o locales, directamente o mediante contactos, acuerdos y convenios de carácter internacional entre instituciones tanto públicas como privadas, dentro del marco de sus competencias 
En este sentido la paradiplomacia se aleja de la proyección exterior propia del ejercicio de los Estados: la diplomacia, pues esta última «trabaja temas ligados a la defensa, la policía, la política monetaria, etc.» (Aldecoa, 2000: 73). En consecuencia, en la paradiplomacia hay algunos contenidos propios de la alta política que quedan expresamente al margen; así es como las materias pertenecientes al núcleo duro de los Estados no pueden formar parte de la paradiplomacia. En sentido contrario, el ámbito de la paradiplomacia queda delimitado por las pertenecientes a la baja política, entre las cuales se destacan las relaciones económicas y las políticas de la sociedad (Cornago Prieto, 2000; Barbé, 1995).

Delimitadas las competencias de la paradiplomacia, la pregunta básica que puede hacerse, es hasta qué punto otros actores, particularmente los Estados con sus gobiernos centrales a la cabeza, van a permitir una real participación de los actores no estatales. Pues, como aprecian Keating y Aldecoa, en general «los Estados no ven con buenos ojos la intrusión de los actores subestatales en

y limitadas a los respectivos territorios. (Tapia Valdés, 2003). Para Mariano Ferrero, se trata de un «conjunto de prácticas de interrelación transnacionales que se superponen parcialmente a la diplomacia (...) Asimismo, estas prácticas no constituyen una (re)producción mimética de los procesos tradicionales de la política exterior, sino que los estilos y estrategias de actuación están marcados por objetivos y motivaciones mucho más concreta y delimitadas» (Ferrero 2006; 7). un área considerada tradicionalmente como de su dominio exclusivo", siendo necesario un cambio de actitud «a fin de aceptar la nueva realidad de poderes compartidos e interdependencia» (Aldecoa y Keating, 2001).

En similar sentido Riordan apunta que «los niveles de gobierno subnacionales, que se impacientan por desempeñar un papel puramente de facto en los asuntos exteriores, están empezando a exigir un papel más representativo y formal», advirtiendo que «los políticos situados en el viejo nivel nacional, deseosos de proteger los poderes y privilegios de que aún disponen, intentan por todos los medios resistirse a esta tendencia» (Riordan, 2003). Aún más, a juicio de Louis Balthazar la experiencia histórica de Québec muestra que «los gobiernos centrales van a tolerar la presencia internacional de algunas de sus regiones tan solo mientras esta no sea demasiado relevante» (Balthazar, 2001). Quizás la solución a este problema y las tensiones que puedan surgir, podría estar, como sugiere Keating, en «alejarse de la idea del poder como un juego de suma cero, en el que un nivel (Europa, los estados o las regiones) debe ganar y el otro perder». "Al contrario,-concluye-creo que es posible desarrollar nuevas vías de reflexión y aprovechar los recursos para el beneficio de todos los niveles» (Keating, 2002).

En síntesis, la paradiplomacia es la intervención de actores y agentes subestatales en la política internacional. No obstante, en palabras de Hocking, más 
allá de las condiciones domésticas que explicaban la participación de dichos entes subestatales en la esfera internacional, los cambios provocados por la globalización han sido el motor primordial que ha impulsado a estos entes a desarrollar una acción exterior (Hocking, 1993: 36).

Con el objeto de profundizar en el fenómeno de paradiplomacia, analizaremos el término protodiplomacia, que si bien se contrapone a esta, ayuda a entender las diferencias en cuanto a los objetivos que se desean alcanzar a partir del despliegue de acciones de algunos actores internacionales. En efecto, si bien los actores paradiplomáticos buscan lo que ya mencionamos -el bien públicodentro de una estrategia secesionista, los actores protodiplomáticos buscan su independencia. Precisamente, en palabras de Aldecoa, la protodiplomacia «es la práctica de las relaciones internacionales por parte de un gobierno no central que aspira a establecerse como Estado plenamente soberano» (1993: 56).

Las gobernaciones, intendencias y municipalidades son uno de los entes de cooperación y competencia internacional a nivel gubernamental. No obstante, no han de ser consideradas las únicas entidades paradiplomáticas. En efecto, a partir de la interpretación genealógi$\mathrm{ca}^{7}$ que James der Derian (1987) hace

la genealogía como método de análisis del termino diplomacia «se dirige a derruir algunos lugares comunes sobre los orígenes de la diplomacia, evita la definición estrecha de los términos, no busca continuidades ni generalidades sino que pone el énfasis en la singularidad de los acon- del neologismo, -para: «junto a», «al lado de», pero también «divergente de», «opuesto a»- la paradiplomacia podría entonces referirse a toda forma de actividad internacional llevada a cabo por actores no tradicionales, incluyendo entre estos las corporaciones transnacionales, las organizaciones internacionales de trabajadores, las comunidades religiosas, los organismos no gubernamentales, la industria, los medios de comunicación (Carreón, 2007).

Según lo expuesto, han de ser susceptibles de calificarse como actores y agentes paradiplomáticos un sin fin de organizaciones e individuos que no se encuentran circunscritos a gobiernos no centrales, pero que generan en su accionar externalidades positivas de interés público. No obstante, es muy importante hacer una distinción entre los actores y los agentes, puesto que precisamente los primeros son susceptibles de ser calificados como interlocutores de las relaciones paradiplomáticas, mientras que los segundos no ${ }^{8}$. En definitiva, no

tecimientos, así como en los «discursos silenciados» (Aguirre, Zabala, 2000: 206). Acontecimientos y discursos que dan cuenta, por cierto, de la emergencia de la paradiplomacia y sus variaciones semánticas.

8 Para el caso particular de América latina, las agencias internacionales (regimenes internacionales) buscan un interés propio sea este económico y político (Hoffmann, 1989), o social y moral (Wendt 1999; Hopf, 1998). No hay que equivocarse sin embargo y pensar que este último se reproduce cabalmente en el subsistema regional o local, esfera de los actores para- 
podemos decir que son actores paradiplomáticos todas las personas, grupos o instituciones tanto públicas como privadas que participan en el sistema internacional. De manera que resueltamente podemos definir como actor paradiplomático «aquella unidad del sistema internacional (entidad, grupo, individuo) que goza de habilidad para movilizar recursos que le permitan alcanzar sus objetivos, que tiene capacidad para ejercer influencia sobre otros actores del sistema y que goza de cierta autonomía» (Barbé 2003: 135). Estos actores paradiplomáticos buscan participar de un programa regional contribuyendo a la gobernanza.

Según Mansbach, (1976: 137) los posibles actores paradiplomáticos son por lo tanto:

a) AGNC: Actores gubernamentales no centrales. Hace referencia a los gobiernos subnacionales, locales y regionales

b) AING: Actores intraestatales no gubernamentales. Se refiere a agrupaciones privadas que actúan al interior del Estado como por ejemplo

diplomaticos (al interior de cada Estado nación), pues los agentes no ayudan a articular lo que denominamos región. No obstante, en Europa hace ya una década, con la entrada de las regiones a la Unión Europea, se discute la idea de «gobernanza multinivel» (Marks, 1993), estrategia que sí posibilitaría la formación de agencias a nivel local con conexiones gubernamentales y a nivel de regímenes internacionales. Aunque que no se ajusta a la realidad latinoamericana. partidos políticos, sindicatos y otros grupos de interés, que se relacionan o interactúan con otros actores internacionales con independencia de sus respectivos gobiernos.

c) Individuos: personas naturales que actúan en el campo internacional amparados en su prestigio personal.

Los objetivos pueden ser de variada índole pero estos, según el concepto de paradiplomacia, no pueden estar marcados por motivaciones muy concretas y delimitadas, puesto que el fin último es la consecuente búsqueda de objetivos sociales que no se reducen simplemente al ámbito corporativo, sino que a un ámbito más global, regional, o social. Se ha dicho que el principal motivo de la paradiplomacia ha sido la consideración económica; no obstante, es posible distinguir una serie funciones que desbordan este campo. Según Michael Keating es posible encontrar tres grupos de razones que de manera directa inciden en la actividad que despliegan las regiones para desarrollar una cada vez más amplia actividad exterior: económica, cultural, y política (Keating, 2001: 14-22).

En el ámbito de la economía la paradiplomacia de las regiones al menos persigue las siguientes finalidades: atraer inversiones extranjeras, atraer la instalación de los centros de decisión relacionados con la alta tecnología, buscar nuevos mercados para sus productos y promover el turismo (Lachapelle y Paquin 2003: 49-53). Los actores gubernamentales no centrales 
logran estos objetivos básicamente mediante políticas de incentivos económicos y de promoción. Mientras que los actores más bien privados, no gubernamentales, dichos objetivos se logran fundamentalmente mediante el lobby ejercido por los altos mandos de las empresas u organizaciones afines.

En el ámbito cultural, la paradiplomacia sirve para buscar apoyos y recursos en la esfera internacional para promocionar su idioma, expresiones cultural es en el seno de las instituciones comunitarias (Gallardo, 2006: 53) y, también se puede agregar, para promover el intercambio cultural y el desarrollo de eventos culturales en conjunto entre localidades o regiones de distinto países, habitualmente fronterizos, con el fin de intercambiar ideas que validen estas nuevas escalas de acción internacional, y que, en última instancia, aportan a la densidad cultural compartida.

Por último, las motivaciones de carácter político se relacionan en el ámbito gubernamental no centralizado con la búsqueda de reconocimiento nacional e internacional y en el ámbito de actores no gubernamentales e individuos con objetivos políticos más específicos, así como con la promoción de proyectos sociales, la solución de ciertas controversias o el apoyo interpartidario, entre otras.

Con todo, está claro que la «paradiplomacia amplía el vínculo mundial del país, moderniza el proceso de toma de decisiones de aquella política y, paralelamente, integra el desarrollo de la ciudad a los contextos que están más allá de sus fronteras nacionales» (Miranda, 2005). En consecuencia, el resultado de la paradiplomacia está siendo el hermanamiento de localidades y la formación de nuevas escalas de acción internacional como la transfronteriza.

\section{LA INSTITUCIONALIDAD CHILENA EN MATERIA DE LA INSERCIÓN INTERNACIONAL DE LOS ACTORES SUBNACIONALES}

Esta tendencia mundial hacia la apertura internacional de los actores subnacionales supone cierto reconocimiento por parte de los actores centrales, quienes tradicionalmente, sobre todo en América Latina y especialmente en los Estados unitarios, monopolizan la acción exterior. Pese a esta exclusividad que ostenta el Ejecutivo en materia de política exterior, no debe desconocerse que "medios parlamentarios vinculados, sea a las comisiones de relaciones exteriores, sea a las regiones, y con más razón, los personeros de asociaciones gremiales de tipo patronal y laboral, están siempre atentos a, y ejerciendo influencia sobre las prioridades y contenidos de las negociaciones con el exterior. (Tapia, 2003:35).En efecto, Chile, respondiendo a este contexto de apertura y nuevas presiones, de alguna manera ha puesto al día su marco institucional en materia exterior. A continuación brevemente lo describiremos: 
La estructura burocrática encargada de dar viabilidad a las acciones exteriores de las regiones chilenas consta de la colaboración de dos carteras: el ministerio de relaciones exteriores y el ministerio del interior. Ambas cumplen funciones claves de coordinación. El primero, a través de la Dirección de Coordinación Regional (DICORE), de la Comisión de Regiones Extremas y de la Dirección de Fronteras y Límites, (DIFROL); el segundo, a través de la Subsecretaría de Desarrollo Regional y Administrativo.

En noviembre de 2001 entre ambas carteras se firma un protocolo de coordinación ${ }^{9}$. El acuerdo se fundamenta en el consenso respecto a que actualmente el desarrollo de las regiones y sus localidades se alcanza, entre otros desafíos, a través de una creciente inserción internacional a nivel subnacional, toda vez que se aprecia un incremento de la actividad transfronteriza e internacional a nivel regional, junto con un sostenido aumento de iniciativas de cooperación internacional descentralizada emprendidas entre actores subnacionales chilenos y principalmente europeos ${ }^{10}$,

$9 \quad$ En Santiago, el 7 de noviembre de 2001 se firma el protocolo de acuerdo de coordinación y de colaboración entre el ministerio de relaciones exteriores y el ministerio del interior.

10 En la última década han aumentado ostensiblemente las experiencias de cooperación descentralizada entre Chile y Europa a través del programa Red URBAL. Financiado por la Comisión Europea, su principal objetivo es a través de este tipo de cooperación promover políticas urba- las que requieren de apoyo y de efectiva coordinación con las autoridades centrales, a fin de que en el diseño de la política exterior de Chile se incorporen la visión estratégica y demandas específicas de las regiones ${ }^{11}$. En este nuevo marco se destacan dentro de las funciones a cumplir las que siguen: las relacionadas con capacitación y apoyo institucional para fortalecer los cuadros regionales en materia de gestión internacional y el fortalecimiento de capacidades de interacción vinculadas a las esferas estratégicas internacionales; la promoción a nivel regional del conocimiento de los alcances de la política exterior junto a su proyección regional y la vinculación con misiones de Chile en el exterior y finalmente, procurar que las actividades internacionales a nivel regional se oficien con arreglo a las facultades que a los gobiernos regionales entrega la ley ${ }^{12}$.

Si bien en Chile, como en la mayoría de los países del continente, no se ha modificado el instrumental jurídico que permita que los actores paradiplomaticos estén investidos de la facultad

nas a nivel local e incentivar la colaboración entre actores locales europeos y de América Latina. Más información en Centro de documentación del Programa URBAL: http://centrourbal.com/redes/intro_purbal.htm.

11 Protocolo de acuerdo de coordinación y de colaboración entre el ministerio de relaciones exteriores y el ministerio del interior: http://www.cooperaciondescentralizada.gov.cl/1511/articles-68383_recurso_1.doc.

12 Ibid. 
de contraer obligaciones en el ámbito internacional, los esfuerzos descritos más arriba se complementan con ciertas concesiones a los gobiernos regionales para desarrollar acciones que han permitido el fortalecimiento de prácticas político administrativas en materia internacional.

En cuanto a las facultades que ostentan los gobiernos regionales, la ley $\mathrm{N}^{\circ} 19.175$ sobre Gobierno y Administración Regional, contempla materias reguladas que se refieren fundamentalmente a cooperación internacional y transporte internacional transfronterizo ${ }^{13}$. Aunque limitada, la

13 Jorge Tapia pormenorizadamente analiza las atribuciones en materia internacional que le corresponden a los CORES: «el ámbito de las atribuciones y funciones del Gobierno Regional propiamente tal, encontramos en primer lugar la norma de la letra g) del art. 16, que lo faculta para "participar en acciones de cooperación internacional en la región, dentro de los marcos establecidos por los tratados y convenios que el Gobierno de Chile celebre al efecto y en conformidad a los procedimientos en la legislación respectiva». Aunque la norma no hace concesiones en materia de jus contrahendi, deja claramente ver que queda abierta la posibilidad de celebrar tratados y convenios de alcance y ejecución regional, lo cual normalmente dará lugar a actividades del Gobierno Regional que correspondería clasificar como «internacionales». Más adelante, la letra d) del art. 17, que establece las competencias del gobierno regional en materia de ordenamiento territorial, prescribe como competencia suya fomentar y velar por el buen funcionamiento de la prestación de servicios, entre otras, en materia de transporte «internacional fronterizo en la región, cumpliendo las normas de los práctica subestatal ha sido más amplia, como se verá en los apartados siguientes referidos a la región de Tarapacá. Un elemento clave sostiene que las disposiciones comprendidas en dicha ley parten de la base de que las autoridades regionales deben tener facultades en materias propias de las relaciones internacionales, que aunque enmarcadas en el jus contrahendi del Presidente de la República y revestidas del carácter de mera aplicación de la norma del gobierno central, suponen aceptar un indispensable grado de autonomía relativa de dichos órganos(Tapia, 2003).

La modalidad utilizada por las regiones chilenas ha sido la suscripción de Convenios que establecen acuerdos marcos o genéricos entre los gobiernos regionales o entre una unidad ad hoc del poder central ${ }^{14}$ y la cotraparte extranjera, que lo suscriben a los cuales, en algunos casos, por la vía de un addendum se les ha anexado posteriormente obligaciones y tareas específicas. (Gallardo, 2006).

convenios internacionales respectivos». $\mathrm{Al}$ igual que en el caso anterior y como la práctica lo corrobora, esta función solo puede cumplirse involucrándose en una intensa y permanente actividad internacional. Por último, todas y cada una de las funciones especificadas en el art. 18 sobre fomento de las actividades productivas, llevan a los gobiernos regionales, particularmente a los de las zonas extremas multifronterizas con carácter de fronteras internas críticas, a estar en cotidiano contacto con sus pares de las áreas transfronterizas ( Tapia, 2003: 38).

14 Es el caso de la SUBDERE. 
Con todo, los gobiernos regionales ejercen acciones que generalmente obedecen a una interpretación flexible de las facultades que poseen en la materia, aunque en ocasiones se entra en contradicción con la lectura más restrictiva que emana de los órganos centrales del gobierno. En este sentido, los municipios, otro actor paradiplomático clave, por su mayor autonomía se encuentran en una posición privilegiada para emprender relaciones tanto transfronterizas como internacionales con una variedad de actores. Diversas leyes han reconocido esta facultad, sobre todo la Ley Orgánica Constitucional de Municipalidades, $\mathrm{N}^{\circ} 18695^{15}$.

A modo de evaluación, a seis años de su funcionamiento, se observa que una de las características de esta nueva estructura en materia internacional subnacional es su baja institucionalización, cuestión que se evidencia en las experiencias dispares de inserción

15 Dentro de las facultades de las Municipalidades en materias internacionales, Jorge Tapia destaca lo siguiente: «se refiere en tres oportunidades a tópicos relacionados con la actividad internacional. La primera, a propósito de la aprobación del presupuesto municipal, materia en la cual exige que el proyecto incluya un anexo informativo sobre «los proyectos presentados a otras instituciones nacionales o internacionales» (art. 65, inciso cuarto, $\mathrm{N}^{\circ} 3$ ). Otra, al definir los objetivos de las asociaciones que pueden formar dos o más municipalidades, especificando que uno de ellos puede ser «La coordinación con instituciones nacionales e internacionales, a fin de perfeccionar el régimen municipal» (art. 135, inciso segundo, letra f). (Tapia,2003:39,40). internacional de los actores subnacionales presentes a lo largo del país. En consecuencia, como señala Abel Gallardo (2006), respecto de la institucionalidad en materia de acción exterior de las regiones, «la evaluación de los instrumentos que se han implementado para ello, de su pertinencia y de su eficacia, es un asunto que cabría considerar e indagar en investigaciones posteriores» (Gallardo, 56).

Abel Gallardo constata que un elemento que limita la institucionalización de las actividades paradiplomáticas emprendidas en Chile es la persistencia de un proceso de descentralización parcial, que ha afectado las capacidades de inserción internacional de las regiones, en la medida en que sus actuaciones en el ámbito exterior no siempre encuentran un marco claro y unánime. En efecto «...la dicotomía descentralización/ desconcentración que ha sido resuelta a favor de la desconcentración de prácticamente todos los ministerios chilenos, permanece en la nebulosa tratándose de las tareas internacionales de la región. En ciertos momentos parece privilegiarse la desconcentración; en otros la descentralización» (2006:57), pese a que la cabeza de las acciones exteriores regionales se encuentra el Intendente en calidad de presidente del gobierno regional, es decir, desde una autoridad descentralizada. 
LOS VÍNCULOS ENTRE LA REGIÓN DE TARAPACÁ ${ }^{16}$ Y LA SUBREgióN ANDINA

Habiéndonos aproximado al renovado contexto internacional y subregional que da cabida a la emergencia de nuevos procesos y actores internacionales, delimitado y discutido el concepto paradiplomacia, y habiendo abordado brevemente la institucionalidad chilena que posibilita la acción exterior de las

16 De aquí en adelante nos referimos a la región de Tarapacá sin considerar la reforma a la división político administrativa del país realizada a mediados del año 2008, que la dividió en dos regiones, creándose la nueva región de (XV) Arica Parinacota. Esta se ubica en el extremo norte de Chile, su frontera Norte limita con el Perú, al sur limita con la Región de Tarapacá, al Este con Bolivia y al Oeste con el Océano Pacífico. La capital regional es Arica. Se conecta con Tacna (Perú) y La Paz (Bolivia), a través de dos ferrocarriles y carreteras internacionales. Esta Región está compuesta por dos provincias: Arica y Parinacota. Su superficie es de 16.873 $\mathrm{Km} 2$ y tiene una población de 189.644 habitantes según el censo de 2002. Está compuesta por las comunas de Camarones, General Lagos, Putre y Arica .En tanto, después de la división la I región de Tarapacá quedó reducida a las provincias de Iquique y Tamarugal, esta última surgida de la misma reforma. Limita al norte con la XV Región de Arica y Parinacota, al sur con la II Región de Antofagasta, al este con la República de Bolivia y al oeste con el océano Pacífico. Está compuesta por cinco comunas: Pozo al Monte, Pica, Huara, Camiña y Colchane. Cuenta con una superficie de $42.225,8 \mathrm{~km}^{2}$ y una población estimada al año $2006 \mathrm{de}$ 286.105 habitantes. regiones, a continuación nos centraremos en la región de Tarapacá, en sus especificidades, características y conexiones subregionales, para a continuación rescatar experiencias paradiplomáticas presentes en esta "región ganadora».

Actualmente Tarapacá se constituye como una región estratégica para el centro-oeste de Sudamérica. Su condición de puente entre el mercado sur asiático y la subregión sudamericana, dinamiza los intercambios presentes en los mercados locales de los países que conforman esta zona. Así, las relaciones comerciales entre Bolivia y Chile, a través de sus puertos de Arica e Iquique ha incrementado ostensiblemente en la última década. Rigoberto Sánchez, señala que estas dos ciudades «compiten por las cargas bolivianas, ofreciendo seguridad, servicios de calidad y líneas navieras principales hacia los mercados de destino (...). Así, la competencia entre los puertos por adquirir la carga boliviana dinamiza la relación comercial entre Bolivia y Chile (brasileña, paraguaya, argentina) destinada al mercado internacional, especialmente al Asia Pacífico. (Sánchez, 2005: 128).

Esta dinámica comercial, junto a sus proyecciones de desarrollo, se remonta a inicios del siglo XX. En efecto, dentro de las propuestas de desarrollo para la región de Tarapacá de la época, Luis Castro destaca el impulso del desarrollo regional «a través de una ligazón matricial con el espacio subregional (Bolivia, el norte de Argentina y el sur del Perú) buscando establecer una conexión estructural para, por una parte, poder 
ampliar mercados donde ubicar los esperados excedentes agrícolas, y por la otra, lograr modernizar la economía provincial mediante el fomento de una infraestructura-caminos, ferrocarriles, puertos- que hiciera viable en el mediano plazo la integración comercial con los países vecinos» (Castro, 2002:27$28)^{17}$.

A este proceso de larga data también han contribuido una serie de acercamientos sostenidos por Chile y Bolivia tras los acuerdos que sucedieron al fin de la Guerra del Pacífico, pudiendose conjeturar que esta serie de acuerdos ha favorecido a una política vecinal y han ofrecido campo para acciones paradiplomáticas de actores presentes en estas fronteras. $\mathrm{Al}$ respecto González indica: «...a pesar de los cien años de un conflicto diplomático, en este plano de los acuerdos bilaterales ha habido avances, a saber: el tratado de 1904, las Convenciones sobre tránsito de 1912 y 1937, la Declaración de Arica de 1953, los acuerdos de Complementación econó-

17 La demás estrategias de desarrollo, íntimamente relacionadas con la señalada, vinculadas a potenciar las conexiones subregionales son las que siguen: «La primera, planteó el fomento de una «industria agrícola» para abastecer un mercado interno que, al amparo de estos planes, tenía que incrementarse significativamente, además de poder llegar a los mercados aledaños (Castro; 2000a). La segunda, remarcó la necesidad de expandir la extracción de minerales no sólo para superar la explotación salitrera, sino también con miras a la existencia de un sector minero en propiedad» (Castro, 2002:27). mica de 1955» (González 2006: 115), pudiendo agregarse, además, el más reciente Acuerdo de Complementación Económica de 1994, junto a la vigente agenda de 13 puntos que contempla un «diálogo sin exclusiones» entre las autoridades de ambos países, inaugurado en 2004, agenda que incluye el tema marítimo, además del desarrollo de la confianza mutua; la integración fronteriza; el libre tránsito; la integración física; la complementación económica; la controversia sobre las aguas del Silala; la seguridad y defensa; la cooperación para el control del tráfico ilícito de drogas y precursores; educación, ciencia y tecnología; cultura, entre otros temas.

En la actualidad, a partir de la consolidación de la Zona Franca de Iquique, la región de Tarapacá está mostrando especiales condiciones para constituirse en una plataforma de servicios $^{18}$, donde el corredor bioceánico sería el producto más emblemático ${ }^{19}$.

18 Tras la firma del acuerdo en agosto del 2009, la Zona Franca de Iquique será incorporada al protocolo de acuerdo comercial que tiene Chile con MERCOSUR (ACE $\left.\mathrm{N}^{\circ} 35\right)$. Se espera consolidar el intercambio comercial con arancel cero entre la ZOFRI y el mercado brasileño.

19 Así lo detalla categóricamente el presidente del directorio de la Sociedad Administradora de la ZOFRI, Felipe Pérez Walker: «Las ventas de la Zona Franca de Iquique (ZOFRI) han venido creciendo sistemáticamente durante los últimos cinco años, alcanzando el 2007 los 2.644 millones de dólares, un nuevo récord histórico. Este se verá sin embargo largamente superado el 2008 , ya que los indicadores muestran un 
Los corredores de exportación a través de carreteras internacionales entre Bolivia, Chile y Brasil se han ido lentamente consolidando, al punto que a finales del 2008 los presidentes de Chile, Bolivia y Brasil anunciaron oficialmente el inicio de las obras de la construcción del corredor que vinculará los tres países

crecimiento este año de un $30 \%$ respecto del año anterior, esperándose llegar a los 3.300 millones de dólares. Esta cifra, solo para apreciarla, supera el total de las exportaciones agrícolas, frutícolas y ganaderas de Chile, es mayor a las exportaciones forestales, las de la industria del salmón, y equivale a su vez a más del doble de las exportaciones de vino. La ZOFRI se ha transformado en la más importante zona franca comercial de Sud América y en el principal y más gravitante centro de negocios del cono sur del continente. Su ubicación geográfica estratégica, su variedad de productos, la diversificación de sus mercados, sumado a la experiencia en comercio internacional de las más de 1.700 empresas allí instaladas, constituyen sus principales ventajas competitivas, permitiéndole operar como un gran centro de distribución, principalmente para Chile, Bolivia, Perú y Paraguay, pero con posibilidades de acceder a más de 300 millones de potenciales clientes. En efecto, el corredor bioceánico en actual construcción, le permitirá no solo penetrar nuevos mercados con su oferta de productos que viene de ultramar, sino también, a la inversa, concentrar una oferta exportable de proyecciones de países de la región que buscan exportar sus productos a través del Pacífico. Entre los mercados de destino de las mercancías de la ZOFRI, Chile concentra el $53 \%$ de ellas, seguido de Bolivia con un $26 \%$, Paraguay con un $9 \%$ y Perú con un $8 \%$, repartiéndose el resto entre varios países (Pérez Walker, 2008: 3). y unirá el Atlántico con el Pacífico ${ }^{20}$, haciendo más compleja la red de interconexión transfronteriza.

Por otra parte, la tendencia mundial actual, apunta hacia una mayor importancia geoestratégica de las triple-fronteras de cara, como hemos señalado en los primeros apartados, a una globalización que presiona por la circulación de bienes, servicios y personas. Estas zonas de integración periférica deberían constituirse como áreas centrales, en la medida en que se consoliden corredores internacionales. No obstante, como señala Witker, «también constituyen zonas en que agentes globales, que giran en torno a asociaciones ilícitas, (narcotráfico y contrabando, fundamentalmente) actúan con cierta impunidad» (Witker, 2005; 131) trayendo, como consecuencia, respuestas contradictorias por parte de las autoridades que cautelan las triple fronteras. Por ello, Grimson

20 Su trayecto pasará por la Amazonía brasileña, el altiplano boliviano y el norte chileno. El $75 \%$ de la ruta está asfaltada y el $25 \%$ restante se encuentra en territorio boliviano en su mayor parte, y se halla en fase de construcción. El corredor unirá los puertos de Santos-Brasil (Atlántico) y Arica-Iquique Chile (Pacífico), pasando por Bolivia. Su extensión será de 6.126 $\mathrm{Km}$., de los que 3.137 pasan por Brasil y 2.989 por Bolivia y Chile. El $75 \%$ de la vía está pavimentado. Su prioridad será Arica, pues este corredor vial se complementará con el ferrocarril Arica-La Paz, en fase de licitación para recuperar el tramo Arica-Visviri y que debe estar funcionando en 2010 (Jonquera Dinamarca, 2009). 
señala que en las fronteras actuales de América Latina la tendencia hacia «el control sobre las poblaciones fronterizas parece haberse fortalecido, tanto en relación a la circulación de personas como de pequeñas mercaderías del llamado 'contrabando hormiga'. Así, en muchos casos, los fronterizos perciben una mayor -no una menor- presencia estatal» (Grimson, 2004: 11).

\section{EL MARCO DE LAS RELACIONES VECINALES}

Las relaciones entre Chile y sus vecinos peruanos y bolivianos presentan una realidad un tanto zigzagueante. Desde el fin de la Guerra del Pacífico, los roces entre Chile y Perú han sido recurrentes. En palabras de Paz Milet nuestros países han vivido siempre afectados por «una relación fluctuante, afectada permanentemente por la herencia del pasado. La Guerra del Pacífico y sus consecuencias más visibles» (Milet, 2004: 228-235), y sostiene que la pérdida territorial y consecuente obtención de trofeos de guerra se convierten en un factor determinante para avanzar en el desarrollo de vínculos.

Aunque en la actualidad la variable histórica está presente, cabe destacar los esfuerzos que se realizan en dirección a un trabajo de colaboración bilateral en el que se destaque la proyección regional. Tal situación es evidente para el ministerio de relaciones exteriores del Perú donde en conjunto con Chile, han acordado "construir una asociación estratégica basada en la creciente convergencia de intereses y voluntad de cooperación entre ambos países» ${ }^{21}$. Así, desde 2001 hasta la fecha se han ido conformando directrices para la consolidación de una agenda de trabajo que incluye temas como la propuesta peruana sobre la reducción de gastos militares; consultas diplomáticas permanentes; la promoción del comercio; el incremento en la cooperación de carácter técnico, tecnológico y cultural; como también la atención a las necesidades de la comunidad peruana residente en Chile y viceversa. Un tema destacado por la cancillería peruana ha sido los avances en materia de desarrollo transfronterizo sostenidos con Chile a través de iniciativas piloto de cooperación descentralizada entre localidades de la triple frontera ${ }^{22}$.Se destaca además

21 Ver más en Relaciones Bilaterales Perú con Chile, en www.rree.gob.pe.

22 Se trata del micro proyecto «Fortalecimiento de la red ganadera de la región trifronteriza Chile, Perú, Bolivia» y del programa «Promoviendo nuestro territorio con identidad: experiencia piloto en las comunidades aymaras de la zona fronteriza de Bolivia, Perú y Chile», ambos en el marco de la cooperación descentralizada sostenida con la región italiana de Toscana y con el asesoramiento del CESPI. Para profundizar el tema, ver: Informe de Gestión 2005-2009 de la Dirección Nacional de Desarrollo Fronterizo del Ministerio de relaciones Exteriores del Perú. Págs.: 80, 81 y SS. En: http://www.rree. gob.pe/portal/enlaces.nsf/3f08cf720c1db f4805256de20052913d/18715afe9515dd f1 $052575 \mathrm{~b} 6005 \mathrm{ff} 33 \mathrm{a} /$ \$ FILE/InfGest11052009.pdf . 
el apoyo de la Dirección Nacional de Desarrollo Fronterizo del Perú a sus municipios fronterizos en materias asociadas a mejorar la gestión pública, temática que también canaliza su homólogo chileno a través de los Comités de Integración y Frontera Chile-Perú.

Surge de esta manera y en estrecha relación con el objeto de estudio de este trabajo -la paradiplomacia- la posibilidad de afirmar que si bien esta no es considerada como un instrumento de primera línea en las relaciones vecinales con Perú, el desarrollo de actividades de tipo local que establecen un intercambio a nivel comercial, educacional o cultural, sí podrían configurarse y vincularse de estrecha manera con una labor paradiplomática.

En el caso chileno-boliviano las relaciones han estado también en permanente entredicho. El último incidente de alto nivel entre ambas naciones se produjo durante la Cumbre de las Américas, en 2004. En la oportunidad los mandatarios de Chile, Ricardo Lagos, y Bolivia, Carlos Mesa, tuvieron un tenso cruce de declaraciones culminando con la ya clásica frase del presidente chileno: «Si de diálogo se trata, ofrezco relaciones aquí y ahora».

Rolando Devia ${ }^{23}$, nos entrega ciertas pistas acerca de las instancias e instituciones factibles de llevar a cabo estos contactos paradiplomáticos, surgidas de un encuentro acerca del tema or-

23 Columna publicada en el diario «La Razón», de La Paz, 21 de febrero de 2007. Disponible en: http://www.la-razon.com/ versiones/20070221_005824/ nota_246_393491.htm ganizado por la Universidad de Viña del Mar, en 2007: «Entre los actores podemos mencionar a los municipios, intendencias, universidades, las ONG, fundaciones e incluso a las mismas personas en forma independiente (...) $\mathrm{La}$ interacción entre las regiones y/o municipios entre países ha demostrado ser eficiente y eficaz. Ejemplos hay muchos. Destacamos la misión empresarial conjunta entre las gobernaciones de Mendoza y Valparaíso en 2004 a China a la que asistieron empresarios locales y cuya visita se materializó en un importante aumento de las exportaciones locales».

El segundo factor que propicia la existencia de estos contactos es, justamente, la inexistencia de relaciones diplomáticas formales entre Santiago y La Paz. La paradiplomacia está llamada a ocupar en este ámbito un rol de primera línea. «Los medios para superar las controversias generadas por la mediterraneidad boliviana estarían en el ámbito de la paradiplomacia. Al no existir vínculos intergubernamentales a nivel diplomático, se desarrollan instancias de acercamiento y diálogo en otros niveles» (Milet, 2004; p. 46).

Las relaciones también afectan otros ámbitos, como el comercial. Por ejemplo, durante el año 2007 las exportaciones a Bolivia alcanzaron a 299, 7 millones de dolares, las importaciones fueron de 56,6 millones (ProChile, 2007: 2). Además, en Chile existe una importante comunidad boliviana, la que se ha acrecentado en los últimos años. De los 258 mil extranjeros regis- 
trados por el Ministerio del Interior, alrededor del $6 \%$ proviene de Bolivia ${ }^{24}$.

Un rol importante en el ámbito de las relaciones paradiplomáticas con ambas naciones lo ha constituido la Zona de Integración del Centro Oeste de América del Sur (Zicosur). Se trata de un proyecto de complementación económica, comercial y cultural, que también se dedica a fomentar la cooperación intergubernamental y empresarial que congrega a las regiones aledañas al Trópico de Capricornio.

\section{Desafíos Y Dificultades ASOCIADOS A LA CONSTITUCIÓN DE REgIONES TRANSFRONTERIZAS}

Bob Jessop (2004) señala que las regiones transfronterizas se han convertido en objetos específicos de políticas y no solo en territorios económicos. Dichas políticas, por las características del fenómeno regional transfronterizo, deben estar basadas en la cooperación descentralizada; en tanto, como hemos señalado más arriba, son «los gobiernos subnacionales [los que] han estado alcanzando un protagonismo nuevo y mayor para la integración social y productiva de las fuerzas locales en las dinámicas globales» (Rhi-Sausi, 2008).

Sin embargo, en la triple-frontera que nos ocupa debe constatarse si estas

24 Desarrollo del Fenómeno de las Migraciones en Chile. Evolución de la gestión gubernamental desde 1990. Ministerio del Interior de Chile. nuevas tendencias pueden efectivamente desarrollarse o, contrariamente, por un lado existen barreras institucionales que las limitan ${ }^{25}$, y por el otro, paralelamente a su avance existen clivajes producto de los tradicionales conflictos nacionalista y étnicos que las frenan.

La triple frontera chileno-peruanoboliviana ha sido tradicionalmente una zona de alta movilidad poblacional. En las últimas décadas la inmigración, además de haber aumentado, ha cambiado su énfasis cualitativo: se ha feminizado (Gavilán y Tapia, 2006) ${ }^{26}$, lo que conlleva una serie de desafíos y respuestas por parte de las autoridades. Conjeturamos, siguiendo la propuesta de González (2006), que esta inmigración presiona por redefinir las relaciones transfronterizas en la zona de la triple-frontera, generando, por un lado, una oportuni-

25 Cabe destacar que, como se señaló en el apartado anterior, la Cancillería no tiene representación administrativa en regiones, por ello, si bien las regiones transfronterizas de Tarapacá se han convertido en objetos específicos de políticas, estas son diseñadas estrictamente por el poder central.

26 Detallando la situación en cuanto a la migración presente en la región, señalan: «La inmigración peruana y ecuatoriana en Chile y en particular en Tarapacá presenta algunos rasgos similares a los señalados por los estudios acerca de la emigración en Ecuador y Bolivia. Se trataría de una migración laboral, con un alto número de mujeres (cuya tendencia al aumento pareciera continuar), con altos niveles de escolaridad y cuya inserción en el mercado de trabajo se caracteriza, en general por ocupar segmentos de mercado de baja calificación (Gavilán y Tapia, 2006). 
dad a la paradiplomacia y, por otro, un desafío frente a la posibilidad de que vuelvan a surgir movimientos xenófobos o nacionalistas, similares a los del período comprendido entre el fin de la Guerra del Pacífico y 1929, desde cualquiera de los tres países. No debemos olvidarnos que, como plantea Phillip Schmitter, mientras mayor sea la participación de la comunidad interesada en intervenir en actividades propias de la integración, actuando libremente con el apoyo de la autoridad, mayor será la posibilidad de reciprocidad entre los interesados y más fácil será la búsqueda de acuerdo entre las partes, logrando mejores condiciones para una respuesta asociativa. Sin embargo, además de aflorar los intereses, también surgen pasiones basadas territorialmente, ya sean planteamientos nacionalistas o étnicos (Schmitter, 1989), los que obedecen a dinámicas conflictivas internas ya sean históricas o más coyunturales, pero -y esto es lo importante- que los procesos de integración periférica pueden activar.

Con todo, las dificultades para consolidar la presencia de estas nuevas dinámicas presentes en la triple frontera se deberían a una serie de limitaciones que frenan la tendencia hacia una mayor autonomía de las regiones para constituirse como actores internacionales con cierto protagonismo: el centralismo, que desincentiva el surgimiento de nuevas racionalidades distintas de la gubernamental ${ }^{27}$; por otro lado, el nar-

27 Así es como para Juan Podestá, la tecnocracia gubernamental y su mirada econo- cotráfico y el contrabando que contradictoriamente endurecen las fronteras, así como la emergencia de conductas xenófobas entre los ciudadanos de regiones receptoras de migración (Arica e Iquique), entre otras causas, minarían estos esfuerzos.

No obstante, a causa de «la perforación de la soberanía» los actores subnacionales que emanan de las regiones, de las ciudades, y de sectores específicos de la administración del Estado han podido internacionalizarse y encontrar un lugar activo en el proceso globalizador (Witker 2005). En la triple frontera, esta tendencia puede observarse en los flujos comerciales generados por la Zona Franca de Iquique, las cargas de los puertos del sur peruano, Ilo y Matarani y los chilenos de Arica e Iquique, en la presencia de las grandes compañías mineras e incluso en acciones de los propios gobiernos. (González, 2006; Sánchez, 2005).

micista apuntan a un conjunto de indicadores y no a las especificidades del país, o a las necesidades de las regiones; de esa manera miden la acción del Estado sobre la base de la relación costo beneficio. Además, visualizan las relaciones internacionales en función de la balanza comercial, operan desde el nivel central y privilegian políticas económicas concibiendo el espacio regional en la dimensión exclusivamente económica» (Podestá, 2003:98) 
Gilberto Aranda et al. • Experiencias paradiplomáticas en la región de Tarapacá...

ACTORES Y EXPERIENCIAS DE

PARADIPLOMACIA EN LA REGIÓN TRANSFRONTERIZA DE TARAPACÁ

Sostenemos que los actores estatales, municipales y civiles que desarrollan un papel paradiplomático, especialmente en zonas transfronterizas, comienzan a adquirir destrezas en el campo de las relaciones internacionales que van más allá de un mero intercambio de bienes o servicios. El principal intercambio es de ideas (González, 2006, Jessop, 2004). Por ello, estos actores pueden llegar a levantar una propuesta de integración y desarrollo para esta triple frontera.

En consecuencia, el resultado de la paradiplomacia en nuestra zona de estudio ha sido la configuración de la región, constituyendo una herramienta eficaz para profundizar los procesos de descentralización de los países involucrados, en la medida en que el aumento de las capacidades internacionales para gestionar el desarrollo regional compartido está validando estas nuevas escalas de acción a través de su «institucionalización social, material y espaciotemporal» (Jessop, 2004). Se trata de enfatizar que será preferible que los acuerdos estratégicos sean socializados por las comunidades partícipes, para darle no solo legitimidad social sino proyección de largo plazo

En este apartado se presentan algunas características de actores paradiplomáticos presentes en la región de Tarapacá. La información que se expone ha sido recopilada principalmente a partir de fuentes primarias específicamente a través de entrevistas a actores clave quienes describieron el accionar de su organización

Un actor con vocación internacional emblemático en el Norte Grande de Chile, específicamente en Iquique, ha sido el ex alcalde Jorge Soria Quiroga. Se trata de un caudillo que «desde la década del 60' ha estado presente en los hechos políticos de la provincia de Iquique. Tratándose de un líder excepcional que ha sido capaz de sobrepasar enormes transformaciones políticas: algunas derivadas del régimen militar y otras impulsadas por dinámicas sociales más globales» (Guerrero, 1997) En este contexto, se trata de quien ha liderado, desde la década de 1960, los intentos por consolidar propuestas de integración física entre el extremo norte de Chile y la subregión. Ha basado en parte su adhesión popular desde 1990 en un discurso político anticentralista ${ }^{28}$ y de un regionalismo que está presente desde siempre en el discurso nortino, producto del abandono que ha sufrido históricamente la región ${ }^{29}$. Se nutre,

28 En efecto, «la lucha contra el centralismo ha sido uno de los caballos de batalla de Soria, a pesar de que al contrario de otras ciudades y pueblos del Norte, la ciudad de Iquique goza de una gran autonomía. En realidad, este discurso es más antiguo que Soria mismo, ya que está muy anclado desde los años treinta en la región. Sin embargo, Soria lo hizo suyo y sirve perfectamente sus intereses, pues le permite federar a los iquiqueños en contra de un "otro lejano y opresivo", culpándolo de las dificultades que enfrenta la ciudad.» (Barozet, 2004,219).

29 Ya en 1935, El Tarapacá a través de su corresponsal en Santiago, La Nación, daba 
además, de propuestas integracionistas con los países vecinos, específicamente con Bolivia ${ }^{30}$, incluyendo la proyección al Asia Pacífico, demostrando así que este problema no le es ajeno al ciudadano común y corriente. No es exagerado hablar del «factor Soria» en las

cuenta del problema del abandono del centro hacia esta región:

De «La Nación» de Santiago

«Aspectos económico, social y político de la subsistencia del norte.»

«...Las opiniones responsables en los diversos s círculos manifiestan una verdadera animosidad en contra de la acción política reflejada en el propio parlamento, donde no se abordan, por lo general, los problemas que afectan a los ciudadanos de esta dura region del pais, no obstante las campanas de prensa y las peticiones colectivas reiteradas... Salvo la accion aislada de uno que otro parlamentario y de algunos representantes del ejecutivo, muchas peticiones y aspiraciones de interés general duermen sin obtener solucion, arguyendose falta de recursos fiscales que aquellos conciudadanos estiman no escasean para lo que interesa al centro del apais.... De alli el odio contra lo que alla se llama centralismo y un regionalismo exhorbitante con miras de independencia, en muchos espíritus. (El Tarapacá Jueves 21 de Febrero de 1935, Iquique: 3).

Las propuestas integracionistas surgidas desde la region hacia Bolivia son de vieja data. El diario El Tarapacá de 1950, registra una serie de iniciativas en este orden: «Pedir a la representación parlamentaria y a las organizaciones técnicas estatales la obtención de un estudio detallado, sobre el proyecto de irrigación de la pampa del Tamarugal con las aguas de los lagos bolivianos y la construcción de grandes centrales hidroeléctricas para la industria del norte, acordó anoche el Centro para el Progreso de Tarapacá» (El Tarapacá. Jueves 17 de Agosto de 1950). relaciones vecinales chileno-bolivianas. En efecto, desde mediados de 2007 cuando Soria debe dejar su cargo por acusaciones respecto de irregularidades en su gestión municipal, una de las principales criticas del sorismo a la nueva alcaldesa, es haber abandonado las propuestas integracionistas del caudillo.

Dentro de sus principales empresas paradiplomáticas pueden mencionarse los siguientes.

En el marco de su administración, en el año 2001, la comisión del consejo municipal de la ciudad de Iquique, propone al gobierno central estudiar una alternativa en la región de Tarapacá de una posible salida marítima para Bolivia. La propuesta se refiere a una concesión o alquiler sin soberanía, a cambio de que el Estado boliviano se comprometa al suministro de agua para la explotación minera del norte de Chile. Lógicamente el Estado central respondió negativamente, pues la propuesta vulneraba la política exterior de Chile, que actúa de conformidad con las cláusulas del Tratado de Paz y Amistad, firmado con Bolivia en 1904.

Bajo su administración también se desarrolló en Iquique el VI Foro Hemisférico de Ciudades Hermanas ${ }^{31}$. Presidi-

31 «Sisters Cities International» es hoy una gran red de ciudades que tiene por objetivo aumentar la cooperación global a nivel municipal, promoviendo la comprensión cultural y estimular el desarrollo económico de sus miembros.Como parte de ese programa «Sister Cities of Miami-Dade» mantiene una potente red de hermanamientos con ciudades del mundo. Busca crear y fortalecer las relaciones entre este 
do por el alcalde Soria y el alcalde del condado Miami-Dade, Alex Penelas, su objetivo fue restablecer y fortalecer lazos en lo económico, social, ambiental y turístico entre todas las comunidades participantes, a demás de generar polos de desarrollo en las áreas involucradas. Cabe destacar que Iquique y el condado Miami-Dade son ciudades hermanas desde 1996 en virtud de un acuerdo firmado bajo la administración de Soria.

También destacan sus innumerables viajes a Bolivia, Paraguay y Brasil para promover un corredor bioceánico que cruce los cuatro países y concluya su ruta al Pacífico por la ciudad de Iquique.

Siguiendo con los actores municipales presentes en la Región de Tarapacá, existe una Asociación de municipios rurales que mantiene no solo una nutrida relación con sus pares bolivianos sino que posee una particular mirada de la integración andina subregional, que es compartida por otros actores regionales ${ }^{32}$. Esta mirada apunta a bus-

condado y otros de Estados Unidos con otras comunidades a nivel de gobiernos locales y municipales( Estrella de Iquique, 15 de marzo del 2004: http://www.estrellaiquique.cl/site/apg/reportajes/ pags/20040315012340.html

32 Así queda de manifiesto en el acta de clausura del Seminario de Integración Fronteriza de la Triple Frontera (Bolivia, Chile y Perú), el realizado el 9, 10 y 11 de marzo del 2008 en la ciudad de Tacna, Perú. En el acta final se establece, entre otras cosas, que la cultura aymara es un componente fundamental de la Triple Frontera y que partiendo de su identidad cultural originaria está abierta a la inte- car una integración que se nutre por la identidad aymara, a la que adscriben las comunas participantes en el proyecto. En Chile los convenios de municipios con homólogos extranjeros han crecido notablemente en los últimos años. Esta tendencia permite a los alcaldes y concejales conocer otras realidades y tender a la complementariedad y a la búsqueda de la reivindicación de intereses comunes en la medida en que se trata de comunas que aspiran a insertarse en el mercado mundial por la vía de la cooperación descentralizada. Desde este espíritu se llega a la alianza estratégica Aymaras Sin Fronteras (AE), «proyecto liderado por el ex alcalde de la comuna de Putre. El ex alcalde de esta comuna, Francisco Humire, es el líder natural de este proyecto que reúne a 56 municipios de los tres países, abarcando una población aproximada de ciento ochenta mil personas, y que ha interesado a organismos internacionales como el Banco Interamericano de Desarrollo (BID) y la ONG CESPI, entre otros. También ha incorporado a gobiernos nacionales como el de Chile, gobiernos regionales como el de Tarapacá y el de Tacna, ONG nacionales

racción con la cultura global. Que estamos convencidos de que la integración de la región transfronteriza de Bolivia, Chile y Perú es un elemento sustancial para el desarrollo de una comunidad transfronteriza. Que somos conscientes de que desarrollo económico y social de nuestras circunscripciones es el anhelo de las poblaciones de los tres países. Que el desarrollo macro regional requiere de la voluntad de las autoridades y población. 
como el Centro de Estudios y Servicios Multidisciplinarios (INTI) de Bolivia» (González et. al, 2008: 38).

En cuanto a la relación que se da entre los municipios y los gobiernos regionales respectivos en el marco de este proyecto, Francisco Humire señala: «Los apoyos de los Gobiernos Regionales son importantes, ya que muchas de las aplicaciones de los intereses de la Alianza pasan por la sensibilidad que ellos y otros agentes regionales tengan hacia el mundo Aymara». Humire considera que ellos tienen las ideas más claras que los representantes de los gobiernos regionales respecto del desarrollo transfronterizo, pero entiende que debe trabajar con ello sin perder su finalidad última: la unidad aymara trinacional. En palabras del propio Humire lo destacable de la Alianza es precisamente su carácter étnico: «nosotros tenemos un sustento cultural que nos hace distintos a otras regiones ya que somos Aymaras. La Alianza busca el otorgar fuerza al movimiento indígena haciendo resurgir una organización que tiene un pasado milenario. Desde tiempos Tiwanaku que esta zona tiene algo especial, una concepción regional con una base étnica que es necesario reivindicar». (Ibid)

En cuanto a sus motivaciones, se trata de una combinación de finalidades económicas y culturales, pues busca nuevos mercados para sus productos, y promoción turística de los territorios; además, la paradiplomacia le sirve para buscar apoyos y recursos en la esfera internacional con motivo de promocionar su expresiones culturales (especialmente su mirada del desarrollo con identidad al amparo del convenio 169 de la OIT). También se puede agregar, como señalamos anteriormente, para promover el desarrollo de eventos culturales en conjunto entre localidades o regiones que son partes del proyecto, con el fin de intercambiar ideas que validen estas nuevas escalas de acción internacional y que, en última instancia, aportan a la densidad cultural compartida.

La relevancia de este proyecto, como señalamos más arriba, radica en que esta propuesta va más allá de un mero intercambio de bienes o servicios, siendo uno de sus aportes más relevantes el intercambio de ideas que dan legitimidad a los actores, pues estarían levantando una propuesta de integración y desarrollo para una zona supranacional (56 municipios de Chile, Perú y Bolivia) Consecuencia de ello, a través de él se estarían validando nuevas escalas de acción internacional mediante su institucionalización social.

Otro actor relevante que hemos destacado es el Instituto Católico Chileno de Migración (INCAMI), que opera en la ciudad de Iquique. Esta es una organización católica que busca principalmente desarrollar una estrategia de acogida y apoyo a los inmigrantes en su proceso de adaptación e inserción sociocultural en países receptores, como es el caso de Chile. Esta agrupación es miembro de la Comisión Católica Internacional de Migración (CCIM), con sede en Ginebra, Suiza. Dentro de sus objetivos destacan «sensibilizar a la Iglesia, organismos 
gubernamentales y de la sociedad civil sobre el fenómeno de la movilidad humana y la necesidad de acogida e inserción de las personas migrantes y en movilidad $»^{33}$. En Iquique, el INCAMI es una entidad que tiene como objetivo amparar a los migrantes de Bolivia, Ecuador, Colombia y Perú, siendo esta última la colonia más numerosa. La labor principal está relacionada con la acogida y orientación en temas de legalidad y capacitación laboral al momento de llegar a Chile. Esta acción es coordinada con sus pares de Perú y Bolivia.

Más arriba señalábamos que la inmigración transfronteriza presente en la región presiona por redefinir las relaciones transfronterizas en la zona de la triple frontera, generando una oportunidad para la paradiplomacia. En efecto, el INCAMI mantiene ciertos vínculos formales con el Consulado de Perú en Iquique. En este contexto, durante el proceso de regularización iniciado en octubre 2007, INCAMI Iquique ofreció sus oficinas en Antofagasta para satisfacer las demandas de peruanos que por problemas económicos no podían llegar a Iquique, donde sí existe consulado.

En este sentido, para el director de INCAMI Iquique, Francisco Murillo ${ }^{34}$, existe una buena coordinación con los actores públicos de la región. "Las cosas han ido mejorando, llevamos 10

33 Disponible en http://www.iglesia.cl/especiales/diamigrante/incami.html . Visitada el 3 de julio de 2009.

34 Entrevista realizada en enero de 2009. años en este servicio, y hace seis éramos como la contraparte. Hoy vemos que la Gobernación tiene un departamento de migración (ve asunto de las visas). Pero puedo comentar que no más de cinco años atrás no se daban visas de trabajo y la gente estaba en condición de irregular, estas personas no podían trabajar. Incluso había una búsqueda de parte de policía de investigaciones, con un control muy estricto, buscando en casas y eran expulsados».

Explica que las relaciones con los organismos públicos son positivas, existiendo un trabajo en conjunto, al igual que un interés por avanzar de manera complementaria. «Si hay problemas en la Intendencia con personas sin trabajo vienen acá, y nosotros derivamos gente para allá. La región tiene un plan piloto, muchos organismos de la sociedad están preocupados por los migrantes. Ahora hay más sensibilidad, vemos que hay una respuesta de la sociedad civil, pues antes éramos como una isla».

Además, conforme a esta preocupación existente en la sociedad, tienen lugar encuentros de trabajo con autoridades locales y de los organismos públicos, donde destaca la labor desempeñada por la Unidad de Asuntos Internacionales (URAI) que recientemente realizó un encuentro relacionado con la inserción de los migrantes una vez establecidos y, en situación de legalidad, respecto a áreas como salud y educación ${ }^{35}$.

35 Se trata del seminario internacional organizado por el gobierno regional de Tarapacá, "Gestión de las Migraciones Limítrofes en la Zona Norte de Chile», reali- 
En síntesis, la labor del INCAMI cuenta con un reconocimiento en la comunidad local. Existe un trabajo en conjunto con las autoridades a través de la Intendencia Regional, Gobernación Provincial, como también con la policía y las universidades. Además es relevante destacar que más allá del aporte en el ámbito laboral, la labor del INCAMI ha dado lugar a una integración profunda de la comunidad peruana en la sociedad donde tiene lugar un verdadero intercambio cultural: "Hay un intercambio de tradiciones, la cocina, fiestas religiosas. Es una integración en niveles populares, que es donde nosotros vamos y no hay xenofobia».

Otro actor relevante ha sido la Cámara de Comercio de Iquique. Esta organización posee variadas formas de coordinación con sus contrapartes en el extranjero, en especial con Perú y Bolivia. Se conecta con ellas a través tanto del sector público como del sector privado. La Cámara de Comercio de Iquique trabaja directamente con la Agenda de Cooperación Internacional del Gobierno Regional. Es mediante esta entidad a través de la cual se realiza la mayor cantidad de actividades que relacionan a Chile y específicamente a la región, con Perú y Bolivia. Una de sus funciones primordiales es la promoción del turismo con los países vecinos, junto con lograr una mayor agilidad comercial. Otra de las instancias que se coordina con esta organización, es la Zona

zado el 24 y 25 de julio del 2008 en Iquique, región de Tarapacá.
Franca de Iquique. Esta opera como eje industrial que tiene por objetivo impulsar y generar nuevas inversiones en la región, relacionándose para ello conjuntamente con Perú y Bolivia.

La directora de la Cámara de Comercio de Iquique, Gloria Delucchi ${ }^{36}$, señala que, principalmente, la organización a través de su accionar ha logrado "permitir que la zona franca vaya operando como un eje industrial para Bolivia y también una oferta portuaria». La Cámara se coordina con otras organizaciones similares en Perú y Bolivia a través de asociaciones gremiales y participa de los Comités de Integración. Además esta organización tiene la experiencia que adquirió en las acciones concretas de intercambio que se desarrollaron en los viajes que efectuó el ex alcalde de Iquique, Jorge Soria, hacia Bolivia para estrechar los vínculos con los comités cívicos, especialmente de Tarija.

Se reconoce que el método de trabajo que utilizan ha resultado bastante eficiente, especialmente, en los temas que, según Delucchi, son de índole paradiplomático; por ejemplo, «en un minuto determinado lo que a nosotros nos interesó fue la eliminación de la Visa que se exigía para los bolivianos al entrar a nuestro país».

Otra experiencia ha sido la de poner en el tapete la urgencia de crear una aduana integrada, en que compartan la misma instalación las autoridades de Chile y Bolivia, y así evitar los problemas

36 Entrevista realizada en enero del 2009. 
que surgen de poseer gestiones aduaneras paralelas (distintos horarios de funcionamiento, estándares y procedimientos); la directora enfatiza que ese fue un caso concreto que ha dado sus frutos ${ }^{37}$.

En cuanto a la dinámica con que opera, la amplia trayectoria de trabajo que tiene esta organización en el contexto de los Comités de Frontera e Integración ${ }^{38}$ permite que en la actua-

37 En junio de este año 2009 comenzó el funcionamiento del complejo fronterizo de Colchane, el cual consistirá en un control aduanero integrado, binacional, entre las autoridades chilenas y bolivianas. Se trata de un edificio en que operarán los controles de ambos países, oficinas e instalaciones, con una superficie de más de 2.200 metros cuadrados. Además, estará concluido el emplazamiento que funcionará como albergue para funcionarios, con habitaciones, casinos y sala multiuso, destacándose que el trabajo conjunto logra una mayor fluidez de la circulación de personas y bienes, sin perder los controles que los Estados recomienden, pero optimizando la eficiencia sin recurrir al mayor uso del recurso humano.

38 En los Comités de Integración con los países vecinos (Argentina, Perú y Bolivia participan los gobiernos de los países vecinos a través de los ministerios de relaciones exteriores que actúan como coordinadores de estos comités. En Chile, la encargada de estos foros es la Dirección de Fronteras y Límites (DIFROL) de la Cancillería. En estos encuentros participan, además, los ministerios de interior, economía y transporte; servicios públicos, como Aduanas, Policía Internacional, Servicio Agrícola y Ganadero, servicio de salud, Carabineros de Chile, gobiernos regionales y municipales, además de otros actores públicos y privados.

Los Comités de Integración son foros bilaterales para tratar temas de interés lidad opere bajo una metodología de trabajo bastante afianzada, la cual es conocida tanto por sus homólogos de Perú como de Bolivia. Una de las características de esta forma de trabajo es que la agenda a tratar en las reuniones es conocida desde el momento en que se hace la convocatoria, enviándose con antelación a la reunión los acuerdos de la última sesión y así dar continuidad y seguimiento a los acuerdos y compromisos adoptados. El contexto donde se inserta esta organización tiene la particularidad de que las convocatorias van dirigidas tanto al sector privado como público y que posteriormente se materializan en las agendas de trabajo. Delucchi aclara este punto diciendo que «cuando recién empezó el comité de frontera no se invitaba a los privados, era netamente enfocado al sector público y sector académico, después se empezó con los privados como las

común del área fronteriza y tienen por objeto facilitar la coordinación fronteriza mediante la formulación de recomendaciones para la adopción de medidas que agilicen el movimiento de personas, vehículos y mercancías a través de la frontera común. Dentro de los temas que tratan, se destacan: la facilitación del tráfico fronterizo, aspectos aduaneros, migratorios, fito y zoosanitarios, de infraestructura y normas de transporte, temas de integración como asuntos consulares, salud, turismo, educación, cultura, deportes y temas de desarrollo local. Estos comités tienen una estructura tanto temática como organizacional, donde se trabaja en distintas mesas cada cual trata un tema particular. Por ejemplo, existen mesas de infraestructura, de facilitación fronteriza, de turismo, educación y cultura, entre otras. 
grandes empresas, por ejemplo en el caso minero de repente por una serie de acuerdos de fronteras».

Uno de los actores paradiplomaticos más emblemático para el caso chileno es el gobierno regional de Tarapacá, particularmente su Departamento de Cooperación e Integración Internacional.

Su misión fundamental es implementar la política de internacionalización de Tarapacá. En el marco de esa política, sus iniciativas se concretan a través de los Comités de Integración y otras actividades como encuentros, seminarios, eventos, ferias, instancias donde se formalizan contactos con sus homólogos del Perú y Bolivia ${ }^{39}$.

Otra importante actividad son las vinculadas a los circuitos turísticos integrados. Al respecto Luis Caucoto,

9 Uno de los ejemplos más notables fue la realización del Seminario de Integración Fronteriza de la Triple Frontera (Bolivia, Chile y Perú) realizado el 9, 10 y 11 de marzo del 2008 en la ciudad de Tacna, Perú. En él participaron representantes de las Cancillerías de Perú, Chile y Bolivia, representantes del gobierno regional de Tarapacá, del gobierno regional de Arica y Parinacota, del gobierno regional de Tacna, de la Municipalidad Provincial de Tacna, de la Asociación de Municipalidades Rurales de Tarapacá, de la Arica y Parinacota, Asociación de Municipalidades Rurales Andinas de Tacna, de Mancomunidades de La Paz y Oruro, de la Alianza Estratégica Aymaras Sin Fronteras, del Observatorio Interregional italiano de la Cooperación al Desarrollo (OICS), de la Provincia Autónoma de Bolzano, Región Basilicata, Centro Studi di Politica Internazionale (CeSPI) y del Instituto Italo Latinoamericano (IILA). actual director de este departamento, señala: «en la gran comunidad de los Lipes existe un pequeño proyecto que tiene que ver con el circuito turístico, donde nos corresponde vincularnos a través de estos poderes locales, con estas municipalidades o algunos representantes de prefecturas o servicios públicos vinculados a estos entes gubernamentales». Las relaciones y contactos se realizan con los departamentos de relaciones internacionales o de las prefecturas o de las gobernaciones.

Existen tres instancias a través de las cuales se desarrollan las actividades: de difusión, de capacitación y gestión de departamentos.

En cuanto a las experiencias, hay dos instancias en donde se concentran el grueso de las actividades: los Comités de Frontera y el Zicosur ${ }^{40}$ :

40 ZICOSUR es un proceso de integración regional de tipo horizontal de una subregión dentro del MERCOSUR. Conforman el área ZICOSUR las provincias argentinas de Salta, Jujuy, Tucumán, Catamarca, Santiago del Estero, Formosa, Chaco, Corrientes y Misiones; los departamentos bolivianos de Cochabamba, Chuquisaca, Santa Cruz y Tarija; el estado brasileño de Matto Grosso do Sul; las regiones chilenas de Tarapacá y Antofagasta; y la totalidad de los departamentos de Paraguay, sin perjuicio de que otros Estados soliciten su incorporación con posterioridad (Acta de Salta, 14 de octubre de 2005). La región comprendida por la ZICOSUR, resulta de particular importancia, no solo por su ubicación geopolítica estratégica, sino también por las múltiples fuentes de recursos humanos, naturales y energéticos que posee, suficientes para enfrentar los competitivos mercados internacionales. La 
«Zicosur surge como ente privado; promovido por Antofagasta. De a poco se ha ido transformando en un foro que está cumpliendo un rol importante al recoger las demandas y alegatos de los gobiernos sub-nacionales, para influir en las políticas centrales, nacionales».

Una instancia de apoyo y experiencia, según el jefe del departamento, es la que ha entregado el propio Intendente. Considerado por él ${ }^{41}$ como: «una persona muy sensible hacia la integración. Está comprometido por su descendencia aymara, es muy sensible al tema de la identidad, el tema cultural. Yo diría que es el Intendente que cuenta con más viajes, los que han sido muy fructíferos, por lo que se ha legitimado una presencia de la región en el espacio internacional».

Se han realizado convenios y misiones, según Caucoto, con logros muy concretos. El salto hacia Zicosur ha

subregión reúne una población cercana a los 30 millones de habitantes, en una superficie de 3 millones 600 mil kilómetros cuadrados. Tiene la particularidad de que sus integrantes no son Estados nacionales, sino unidades administrativas subnacionales. A excepción de Paraguay, son economías de menor desarrollo dentro del esquema de las naciones a las que pertenecen. Contribuyen a esta situación las carencias de infraestructura y una situación de desequilibrio básico con relación a los grandes centros de producción y consumo.» En sitio web ZICOSUR: http:// www.zicosur.net/Nueva_ZICOSUR/espanol/index1.php?pag=descripcion.

41 Se trata del ex intendente de Tarapacá, Pablo Valenzuela Huanca, quien ocupó el cargo entre enero de 2008 y noviembre del mismo año. sido sumamente importante ya que se ha transformado en un elemento protagónico, lo que se ha dado básicamente por la fuerza que le ha puesto la Presidenta en terminar este corredor interoceánico, lo que es bastante interesante porque puede constituirse en un eje que conecte con Zicosur.

Por otra parte, en cuanto a la gestión migratoria, el señor Caucoto reconoce una importante experiencia y la intención de implementar en el país, distintas experiencias de trabajo como la que conoció en México durante una pasantía. «Ahí está la coordinadora de relaciones internacionales. Conocí el modelo que tenía esta coordinadora y estoy tratando de impulsarlo acá. Una característica es que operan bajo una autonomía importante. Contaba con 25 funcionarios y todos eran egresados de la carrera de relaciones internacionales. Lo que yo quiero implementar es eso, por ejemplo, tenían una unidad encargada de la unión europea, otros encargados de Sudamérica; queremos hacer eso. Pero el único problema son las trabas para ponerlo en el organigrama». Existe también un importante trabajo con la pastoral. «Hicimos un seminario [ver nota al pie $\mathrm{N}^{\circ} 26$ ] muy interesante donde invitamos a representantes de los servicios públicos involucrados con el tema migratorio».

En cuanto al impacto de las iniciativas destacadas, Caucoto rescata el hecho de que la prensa está al tanto de sus actividades y que una de las cosas en las que hay que trabajar es difundir y promover en la ciudadanía los temas 
y avances, situación en la que aún hay mucho que trabajar. "Yo creo que la gente percibe los avances porque la visión que se tiene de Bolivia desde el centro es distinta a la visión que se tiene desde la región, en términos de que para el centro de Bolivia no significa nada, pero para nosotros nos significa el $80 \%$ de las exportaciones: si hay problemas con Bolivia decae el crecimiento en la región, por lo que es importante establecer una dinámica más integradora».

Sobre la proyección a futuro, se muestra bastante optimista. "acá hay una proyección enorme. Ahora vamos a una misión a Italia, con proyectos concretos. Vamos a presentarlos para lograr recursos de la cooperación internacional»

En el año 2004 firmaron un convenio de cooperación con el gobierno regional de Tacna, en el marco del Comité de Frontera entre Chile y Perú. El convenio consiste básicamente en intercambiar experiencias de interés común. Se desarrollaron una serie de actividades, como por ejemplo en la subcomisión de fomento productivo, acciones vinculadas al repoblamiento y a la pesca artesanal del recurso machas en la zona fronteriza. Según Caucoto: "Le ofrecimos reactivar el convenio porque a ellos les interesa mucho estar más contactados con nosotros en términos de lo que significa Iquique, que ahora por todo su desarrollo es más que Arica, porque para ellos Tacna-Arica es una sola cosa. Invitamos al gobierno regional de Tacna a participar en unas actividades acá, ya que queremos reac- tivar el proyecto, pero con el conflicto pendiente del royalty [en Perú] está postergado».

Caucoto afirma que en la elaboración del discurso se ha logrado un importante impacto en el gobierno central. Sostiene que hay una apertura que ha permitido mayor libertad de movimiento entre los miembros de los distintos proyectos. Por ello, la misma Dirección de Fronteras y Límites (DIFROL), ha asumido como válido la emergencia de actores paradiplomáticos. Existe mucha disposición a plantear nuestros temas regionales: "hemos logrado incorporar temas vinculados a la cultura, la trata de personas, el VIH. Hay varios temas locales que están incorporados en la agenda, lo cual significa para nosotros una muy buena percepción, sobre todo porque los temas nuestros están siendo incorporados en las agendas nacionales».

Otro actor destacado han sido los Consejeros Regionales de Tarapacá. En general, el rol que cumplen en materias paradiplomáticas es principalmente abrir y establecer los primeros contactos con sus homólogos de Perú y Bolivia, y en un segundo momento constituir espacios de integración y cooperación con regiones, como por ejemplo Oruro en Bolivia y Tacna en Perú.

En este marco se efectuó una entrevista con el ex Consejero a cargo de la comisión de relaciones internacionales, Jaime Valenzuela ${ }^{42}$, quien nos explicó

42 Consejero Regional de Tarapacá entre 2004 y 2008.La entrevista se le realizó en enero de 2009, pues su cargo se extendió 
que la labor que desarrollan es principalmente abrir espacios y establecer contactos tanto en Bolivia como en Perú. Tal como lo menciona: «nosotros podemos avanzar en muchas cosas abriendo caminos, contactándonos con autoridades de otros países, con amigos empresarios. Son iniciativas que uno puede hacer, pero muchas veces se duplican funciones, siendo que deberían concretarse a través del gobierno regional, desde su departamento». Él cree que los contactos deben afinarse y concretarse en convenios de cooperación e integración, lo que solo es posible con la intervención directa de la autoridad máxima de la región, en este caso del Intendente. Se reconoce que durante este gobierno a nivel central existe la voluntad de establecer contactos con Bolivia -al menos en el discurso-y con Perú, esto muchas veces a juicio del consejero Valenzuela no se transmite a las autoridades regionales. Esta situación cobra mayor importancia en zonas transfronterizas como la región de Tarapacá. Valenzuela plantea que actualmente a propósito del contexto de la globalización «hay una verdadera demanda por ir concretando los acercamientos entre distintos actores y participar no solamente como gobierno regional, sino ir armando esta trama público-privado, y cada vez haciendo partícipe a las empresas privadas».

El Consejo Regional ha desarrollado muchos esfuerzos por reimpulsar la

hasta marzo del 2009, fecha en que asumieron funciones los nuevos consejeros. participación de la región en el marco de la ZICOSUR, sin embargo, este proceso ha sido lento, en contraste con lo que pasa, según Valenzuela, en la región de Antofagasta, donde las autoridades regionales han tomado el liderazgo de esta agrupación intentando darle una orientación no solo comercial a dicha instancia. Para él «Hoy día este gobierno regional está inserto en una organización que es fundamental como ZICOSUR, en la que se concentra todos los gobiernos subnacionales de esta gran área; además, están alejados de los núcleos de poder de los centros de cada gobierno».

Finalmente, la dinámica que caracteriza las acciones que desarrolla el Consejo ha estado marcada por un avance lento en sus objetivos. Según esta entrevista ello se debe a dos razones fundamentales, primero la falta de coordinación entre el nivel central y las autoridades regionales y segundo, a que la normativa vigente en estas materias no permite que los acercamientos que ellos establecen con sus homólogos de otros países sean formalizados por la autoridad central o que por lo menos sean estudiados y se dé una respuesta formal. Actualmente, es necesario que a las iniciativas que pueda haber establecido un consejero se le realice algún tipo de seguimiento, tanto por la Intendencia o por el nivel central.

El impacto de las iniciativas emprendidas por el Consejo Regional todavía no es dimensionado en su totalidad, ya que aún no se asume que la región presenta condiciones extremadamente 
favorables para la integración. Por ejemplo, la región goza de una ubicación estratégica con un acceso vial y marítimo inmejorable que permitiría generar incentivos para desarrollar una verdadera estrategia de integración social, económica y cultural con los países vecinos: «entonces, accesos viales, puertos y una zona de integración de zona franca, que no lo es por los hoteles sino por los servicios que da a otros países son a mi juicio, los tres puntos más importante para que esta región tenga más desarrollo».

\section{Conclusiones}

Las actividades paradiplomáticas emprendidas desde la región de Tarapacá en el marco de su proyección subregional han alcanzado un protagonismo importante. Una de las características constantes de las experiencias estudiadas es la vinculación público-privada que se alcanza entre los actores, conformando un círculo virtuoso: universidad-empresa-sector público, sinergia que permite construir una visión estratégica para el desarrollo de la subregión. Otra característica ha sido que las autoridades homólogas de las regiones y comunas de los países vecinos, tanto privadas como públicas, prefecturas, municipios, gobiernos regionales, cámaras de comercio y turismo, han alcanzado una coordinación importante con avances en la misma tendencia. Destacamos también la participación en iniciativas de coope- ración descentralizada, sobre todos los municipios, para el desarrollo que les ha permitido conocer experiencias y obtener financiamiento europeo para consolidar proyectos paradiplomáticos.

Considerando la tipología de paradiplomacia descrita por Eric Philippart $(1997)^{43}$, podríamos señalar que las experiencias en esta región ganadora oscilan entre la paradiplomacia mínima y mayor.

Su clasificación de cuatro tipos de paradiplomacia (mínima, menor, mayor, protodiplomacia) recoge cinco variables: extensión geográfica de la acción internacional, métodos operatorios, intensidad de conflictos con la autoridad central, presencia de liderazgo regional que incentive el regionalismo y su relación con organismos internacionales. Estas variables van evidenciando, en una lógica de menor a mayor complejidad, que a medida que las experiencias recogidas se van acercando a la identitaria o protodiplomacia, van surgiendo mayores fricciones con los actores estatales, se van diversificando los intercambios hasta alcanzar el umbral transnacional, se van generando liderazgos locales que chocan con las lógicas estatales y se van autonomizando los vínculos con organismos internacionales evidenciando la existencia de los fenómenos glocales descritos más arriba.

43 En su tipología de la paradiplomacia, Eric Philippart propone cuatro categorías: la paradiplomacia mínima, la paradiplomacia menor, la paradiplomacia mayor y la protodiplomacia. 
En cuanto a la extensión geográfica de la acción internacional, la paradiplomacia presente en la región de Tarapacá se ajusta a la paradiplomacia menor. Se trata fundamentalmente de relaciones transfronterizas con Bolivia, Perú y el centro oeste sudamericano y en menor medida, transregionales. Resulta interesante destacar que los vínculos transnacionales han sido llevados a cabo principalmente por el municipio administrado por el ex alcalde Soria (viajes a China, feria china en Iquique, foros internacionales de alcaldes, etc.)

En cuanto a los métodos operativos, podemos afirmar que se caracterizan por ser de tipo cooperativo con acciones paralelas armoniosas, emprendidas con los actores estatales. No obstante, se aprecian limitaciones institucionales como la falta de coordinación entre las autoridades regionales y centrales y las limitaciones propias de un marco normativo restringido. Por otro lado, a nivel regional se consolida un entramado cada vez más amplio y participativo de conferencias sectoriales, comisiones asesoras, comités intersectoriales, etc. de corte económico-comercial, como es el caso de los comités de integración, donde se aprecia un nutrido vínculo público-privado encabezado por la Cámara de Comercio de Iquique, entre cuyos logros se destaca el haber impulsado la constucción del Complejo integrado Huara-Colchane.

A su vez, los ámbitos de acción son múltiples, aunque prioritariamente se desarrollan en el terreno económico, principalmente orientado a potenciar el comercio transfronterizo y su facilitación en materia aduanera. Dichos ámbitos son también culturales y con la intención de resaltar elementos identitarios (aunque no necesariamente se trate de protodiplomacia). Es el caso del proyecto $^{44}$ liderado por la organización de municipios "Aymaras Sin Fronteras», en el cual la identidad aymara es un recurso relevante para posicionar el mundo andino en la globalización. En materia educativa a través de la cooperación técnica entre universidades y actores públicos y privados.

Siguiendo con los ámbitos de acción, la experiencia del alcalde Soria se acercaría a una paradiplomacia mayor, en la medida en que en su gestión han surgido reiterados desencuentros o conflictos con el gobierno central, incrementados por la eventual superposición de competencias. A su vez, incluye acciones a nivel político.

La intensidad de los conflictos con la autoridad central se ajusta también a la diplomacia menor, pues eventualmente obedecen a que si bien el gobierno central está informado y participa en el manejo de las políticas elegidas, en ocasiones limita sus opciones cuando estima son materias que pueden afectar la dirección de la política exterior, sobre todo vecinal. Ejemplo de ello es el retraso de algunas obras viales de

44 El proyecto liderado por esta organización es «Recuperación, Fomento y Puesta en Valor del Patrimonio Cultural y Natural Aymara", implementado con el financiamiento del BID. 
carácter transfronterizo (ruta Huara Colchane, demora en habilitación de complejo integrado de aduana).En efecto, el centro siempre debe estar presente en las iniciativas locales que supongan vínculos internacionales (Aymaras Sin Fronteras).

En este sentido, la duplicación de iniciativas y la posible fricción entre actores locales y nacionales, puede observarse en que "ZICOSUR tiene una misión que es idéntica a la iniciada por el alcalde de Iquique, salvo que en este último caso el representante del Estado chileno es un agente directamente nombrado por el Presidente de la República, el Intendente» (Zamorano, 2007:316).

La presencia de liderazgos regionales que incentiven el regionalismo, es muy limitada, pues el clivaje o eje regionalismo-centralismo no define las opciones de las fuerzas políticas regionales, salvo relativamente el caso de Jorge Soria, que ha podido presionar a las autoridades centrales para que tomen cartas en el asunto (puesta en marcha del proyecto de corredor bioceánico). Además, como hemos visto, si bien el anticentralismo y el regionalismo son prerrogativas de vieja data en la región, nunca han definido o permeado las opciones políticas con representación popular del país (notas al pie 19, 20 y 21). Por otro lado, la falta de incentivos políticos, como es la falta de una autoridad regional electa atenta contra las opciones regionalistas.

En cuanto a su relación con organismos intencionales, el ámbito que queda expresado en esta investigación se cen- tra en la cooperación descentralizada y el apoyo de organismos internacionales para el desarrollo (el BID co-financió el proyecto Aymaras sin Fronteras) Uno de los ejemplos más notables fue la realización del Seminario de Integración Fronteriza de la Triple Frontera (Bolivia, Chile y Perú).

Finalmente, podemos señalar que la atención que presten los medios y la comunidad en general a estas actividades paradiplomáticas cambiará en la medida en que realmente existan avances concretos en materia de integración subregional. Además, estas actividades generan en la comunidad una mayor apertura a desarrollar temáticas que redundarán, si se concretan, en un fuerte desarrollo de la zona, por ejemplo desarrollar una infraestructura adecuada para sostener un proyecto tan importante como el corredor bioceánico, es decir, si no existen carreteras de buen nivel y no hay puertos habilitados el tema nunca logrará concretarse lo que en definitiva perjudicará no solo a los empresarios que trasladarán sus productos por estas vías sino a la comunidad en su conjunto.

Por otro lado, el eje articulador de la relaciones transfronterizas han sido los "comités de integración", instancias en que activamente proponen iniciativas paradiplomáticas los consejeros regionales, la Cámara de Comercio de Tarapacá, los gobiernos regionales y municipios rurales, demostrando cierta efectividad en sus propuestas.

Finalmente, la consolidación de estos procesos debería ser el resultado 


\begin{tabular}{|c|c|c|c|c|c|}
\hline 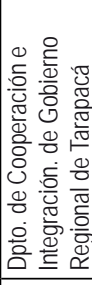 & 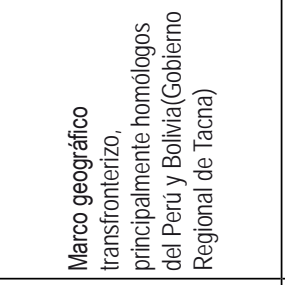 & 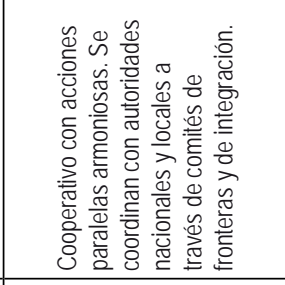 & 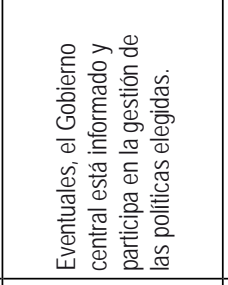 & 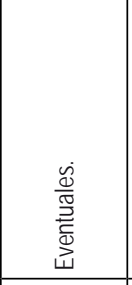 & 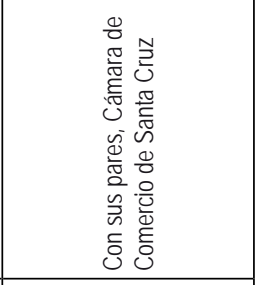 \\
\hline 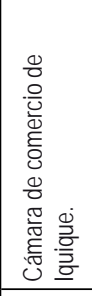 & 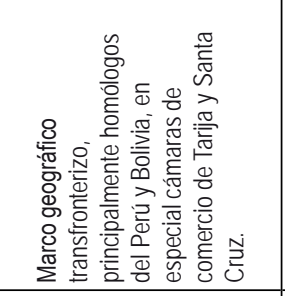 & 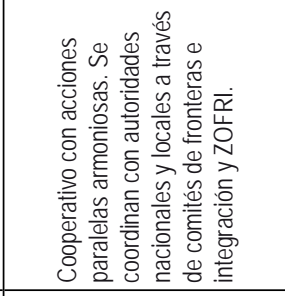 & 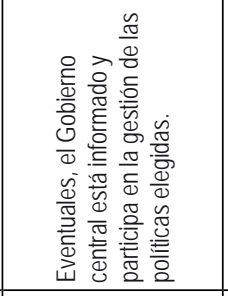 & 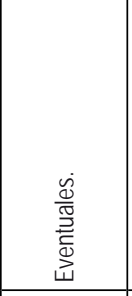 & 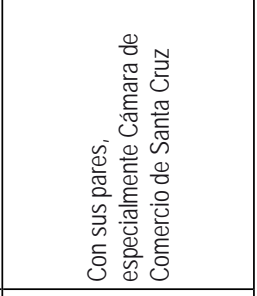 \\
\hline 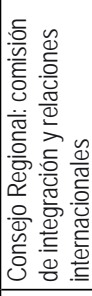 & 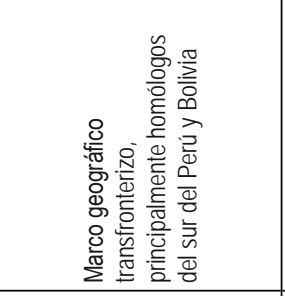 & 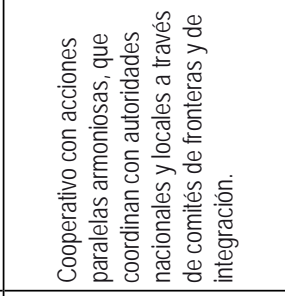 & 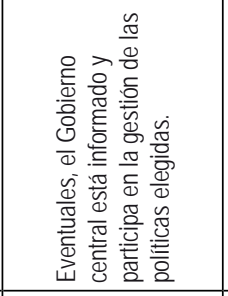 & 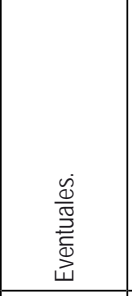 & 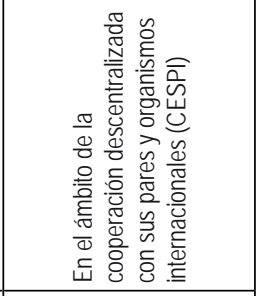 \\
\hline 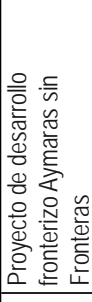 & 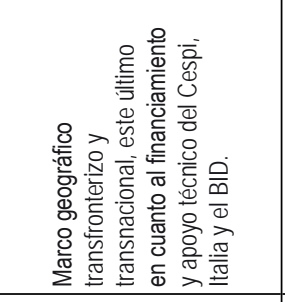 & 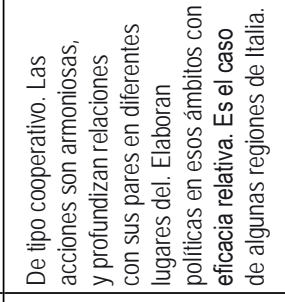 & 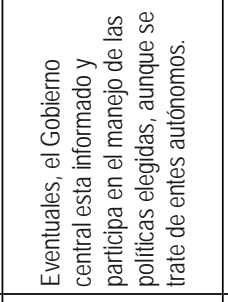 & 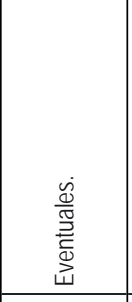 & 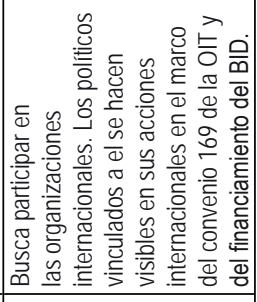 \\
\hline 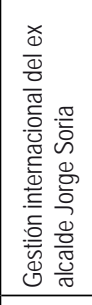 & 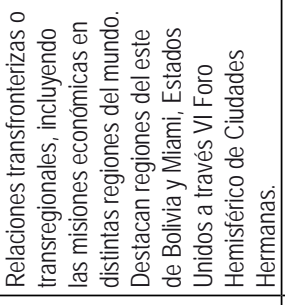 & 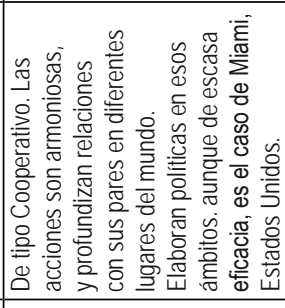 & 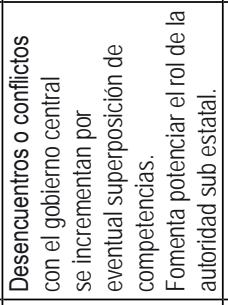 & 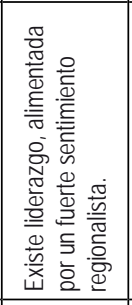 & 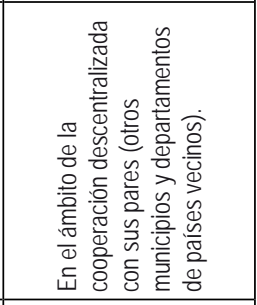 \\
\hline 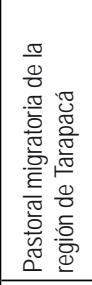 & 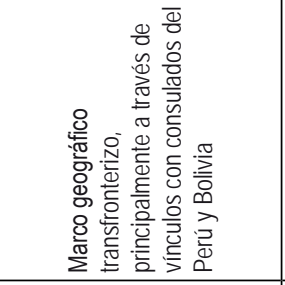 & 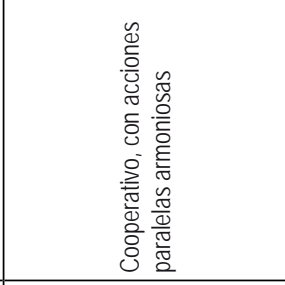 & 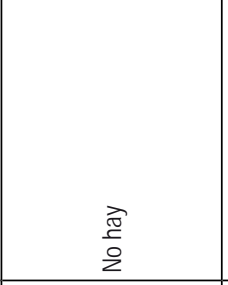 & $\frac{0}{\bar{\Sigma}}$ & 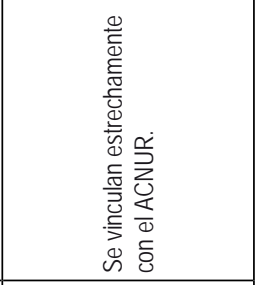 \\
\hline & 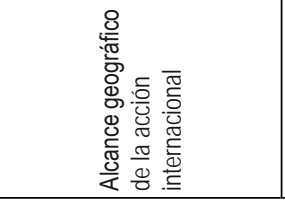 & 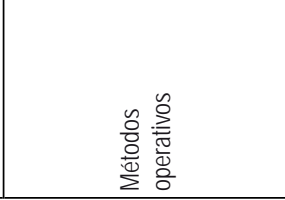 & 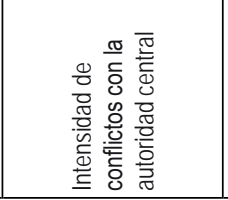 & 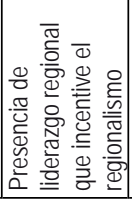 & 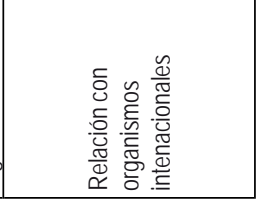 \\
\hline
\end{tabular}


de una sinergia que todavía requiere de una mayor densidad sociocultural positiva entre nuestras naciones

\section{REFERENCIAS}

Aldecoa, F. (2000) La paradiplomacia en la Union Europea, en F. Aldecoa y M. Keating (eds). Las relaciones internacionales de las regiones, Madrid; Marcial Pons, p. 73.

Aldecoa, F. y , M. Keating (eds.) (2000). Paradiplomacia: las relaciones internacionales de las regiones. Madrid: Marcial Pons: 29-54.

Balthazar, L. (2000). La experiencia de Quebec: ¿éxito o fracaso?, en F. Aldecoa, y M. Keating (eds.). Paradiplomacia: las relaciones internacionales de las regiones. pp. (163-181), Madrid; Marcial Pons.

Barbé, E. (2003), Relaciones Internacionales, Madrid, Editorial Tecnos, $2^{\mathrm{a}}$ ed.

Barozet, E. (2004), Elementos explicativos de la votación de los sectores populares en Iquique: lógica y eficiencia de las redes clientelares, Revista Política, (43), pp. 205-251.

Carreon, P. (2007) Paradiplomacia y su desarrollo en el mundo. El fenómeno de los gobiernos no centrales activos internacionalmente, Revista Protocolo, Foreign Affairs \& lifestyle online. http:// www.protocolo.com.mx/autores.php?id_ autor $=65 \&$ all_articles $=1$.

Castro, Luis (2002), «El temprano regionalismo de los tarapaqueños durante el ciclo salitrero: de los discursos económicos a la identidad socio-cultural, 1880-1930", Revista de Ciencias Sociales (12).

Couffignal, G. (2002), El papel del Estado en un mundo globalizado. El caso de América Latina, en Revista del Doctorado en el Estudio de las Sociedades Latinoamericanas, Santiago Universidad ARCIS, pp. 35-51. Cornago, N. (2000), Paradiplomacia; en F. Aldecoa. y M. Keating, (eds.). Las Relacio- nes Internacionales de las Regiones (p.56), Barcelona, Marcial Pons.

Cornago, N. (2000), Diplomacia, Paradiplomacia y Redefinición de Seguridad.

De Marsillo, E. G. (2006), Relaciones Paradiplomáticas: de la teoría y metodología al estudio de las realidades. Algunos aportes al análisis del caso argentino, trabajo presentado en el III Congreso de Relaciones Internacionales del Instituto de Relaciones Internacionales de la Universidad de La Plata (IRI), 28 pp.

Der Derian, J. (1987), On Diplomacy: a genealogy of western estrangement, en Carreon, Pedro (2007), Paradiplomacia y su desarrollo en el mundo. El fenómeno de los gobiernos no centrales activos internacionalmente, Revista Protocolo, Foreign Affaire \& lifestyle online: http:// www.protocolo.com.mx/autores.php?id_ autor $=65 \&$ \&all_articles $=1$

Devés, Eduardo (2002), «Espacio intelectual, integración latinoamericana y sociedad civil: la planética y la ubicación de un nicho en el medio ambiente global», en Estudios Trasandinos. $\mathrm{N}^{\circ} 7$, primer semestre, Universidad de Santiago de Chile.

Díaz, M. (2004), Un nuevo ciclo en la política exterior de Chile: Enfrentando desde América Latina los cambios globales, en Diplomacia (98).

Ferrero, M. (2006), La glocalización en acción: regionalismo y paradiplomacia en Argentina y el Cono Sur latinoamericano, en Revista Electrónica de Estudios Internacionales (10), España, AEPDIRI, p. 7

Gallardo, A., (2006). Paradiplomacia. La dimensión subnacional de las relaciones internacionales. Tesis para optar el grado de Magíster en Estudios Internacionales, Universidad de Chile.

Gavilán, V. y Tapia, M. (2006), Diagnóstico de los procesos migratorios en el norte de Chile, en Revista Electrónica Parinas, Vol II, Nº1, Disponible en: http://www. inteunap.cl/parinas2006/

González, S. (2006), Densidad, integración $y$ conflicto en la triple frontera (Perú, Bolivia, Chile), Serie integración social 
Gilberto Aranda et al. • Experiencias paradiplomáticas en la región de Tarapacá...

y fronteras, Convenio Andrés Bello. pp.: 26 y 27.

González, S. L. Rouviere. C. Ovando, «De «Aymaras en la Frontera" a "Aymaras Sin Fronteras», los gobiernos locales de la triple-frontera andina (Perú, Bolivia y Chile) y la globalización», Revista Diálogo Andino, Departamento de Antropología, Geografía Historia, Universidad de Tarapacá Arica-Chile (en prensa).

Grimson, A. (2004), Fronteras, Naciones y Regiones, Agenda Posneoliberal, Quito. Disponible en: http://www.mujeresdelsurafm.org.uy/agenda_pos/pdf/4a_edicao/ alejandro_grimson_esp.pdf

Guerrero, V. (1997), «Populismo en el sistema político chileno: el caso de Jorge Soria, alcalde de Iquique», Revista de Ciencias Sociales (7).

Hernández, A. (1997), Federalismo, autonomía municipal y ciudad de Buenos Aires en la reforma constitucional de 1994, Buenos Aires; Ediciones Depalma, p.190.

Hocking, B. (2000), "Vigilando la frontera: globalización, localización y capacidad de actuación de gobiernos no centrales», en F. Aldecoa y M. Keating, (eds.); Paradiplomacia: las Relaciones internacionales de Regiones, Barcelona, Marcial Pons, p. 30.

Hocking, B. y M. Smith, (1990), World Politics, An Introduction to International Relations. Londres: Harvester Wheatsheaf; ( $2^{\text {a }}$ ed, 1995), Londres, Prentice Hall/ Harvester Wheatsheaf.

Hoffmann, S. (1989), «The European Community and 1992", Foreign Affairs, Vol. 68, No. 4

Hopf, T. (1998), «The promise of constructivism in International Relations theory». International Security, 23 (1): pp 171-200.

Marks, G. (1993), «Structural Policy and Multinivel Governance in the EC», en A.W. Cafruny, The State of the European Community, Vol.2: Boulder/Harolw.

Milet , P. (2004). Chile-Perú: Las dos caras de un espejo, Revista de Ciencia Politica, Vol XXIV (2) pp.228-235.

Milet, P. (2004). Chile-Bolivia: Cien años después, Revista Fuerzas Armadas y Sociedad. Año 18(1-2).p. 46
Ministerio del Interior de Chile, Desarrollo del fenómeno de las migraciones en Chile. Evolución de la gestión gubernamental desde 1990.

Morgenthau, H. (1986). Politica entre las naciones. La lucha por el poder y la paz, Buenos Aires; Grupo Editor Latinoamericano.

Hocking, B. (1993), Localizing Foreign Policy: Non-Central Governments and Multilayered Diplomacy, Nueva York, St. Martin's Press.

Keating, M. (2000), «Regiones y asuntos internacionales: motivos, oportunidades y estrategias», en F. Aldecoa, y M. Keating, (eds.). Paradiplomacia: Las Relaciones Internacionales de las Regiones, Barcelona; Marcial Pons, p. 14.

Mathews, J. (1997), "Cambio de poder», en Foreign Affairs en Españo, Enero-febrero. Disponible en: www.foreignaffairs-esp. org/

Jessop, B. (2004). La economía política de la escala y la construcción de las regiones transfronterizas, EURE (Santiago). [online] vol.30(89) [citado 13 Enero 2009], p.2541. Disponible en: http://www.scielo.cl/ scielo.php? script $=$ sci_arttext $\&$ pid $=$ S0250$71612004008900002 \& \operatorname{lng}=$ es \& $\mathrm{nrm}=\mathrm{i}$ so>. ISSN 0250-7161.

Jorquera Dinamarca, M., El Morrocotudo, 9 de enero de 2009. Disponible en: http:// www.elmorrocotudo.cl/admin/render/ noticia/18623

Keohane, R. y Nye, J. (1988). Poder e Interdependencia Compleja. La política Mundial en Transición, Buenos Aires; Grupo Editor Latinoamericano. pp. 41-47.

Miranda, R. (2005), «Paradiplomacia y gobierno local: indicios de un modo diferente de hacer relaciones internacionales». Anuario del Instituto de Relaciones Internacionales. Universidad Nacional de la Plata, Universidad Nacional de Rosario, Argentina. Disponible en: http://www. catedrapia.com.ar/Trabajos \%20Roberto/PARADIPLOMACIA $\% 20 \mathrm{Y} \% 20$ GOBIERNO\%20LOCAL, \% 20INDICIOS\%20DE\%20UN\%20MODO\%20 DIFERENTE.pdf 
Moreau Defarges, P. (1993). «Logiques régionales et mondialisation", en Ordre et désordre dans le monde: Cahiers français, La Documentation française, p. 74.

Pérez Walker, Felipe. (2008), «ZOFRI: el portaaviones de Asia de Asia Pacífico para llegar a Sudamérica», Boletín Asia Pacífico. $\mathrm{N}^{\circ} 4$ /diciembre.

ProChile (2007), Comercio Exterior ChileBolivia, Departamento Desarrollo Estratégico, p. 2

Paquin, S. y G. Lachepelle, (2003), «¿Por qué las regiones tienen relaciones internacionales?» en F. Morata, G Lachapelle y S Paquin, (eds), Globalización, Gobernanza e Identidades, Estudios n ${ }^{\circ} 12$, Fundación Charles Pi y Sunyer DÉstudies Autonómics i Locals, Barcelona.

Philipart, Eric (1997), «Le comité de regions confronté à la paradiplomatie des règions de l'Union Européenne», en Jacques Bourrinet(dir), Le Comité des Regions de l' Union Européenne, Paris, Económica.

Rhi-Sausi, J. (2008), La cooperación internacional en los procesos de descentralización y regionalización de los países latinoamericanos. La experiencia Italia-Región de Atacama. Centro de Estudios de Política Internacional (Cespi) Roma, Italia. Revista OIDLES - Vol. 1(3). Disponible en: http:// www.subdere.gov.cl/paginas/programas/ pugr/paginas/globalizacion/sausi.pdf

Riordan, Shaun (2005), Adiós a la diplomacia, Madrid, Siglo XXI.

Rouquie, A. (1987), Amérique Latine? Introduction à l'extreme Occident, Paris, Seuil, p125.

Rouvière, L. (2007). ¿Un territorio político transfronterizo? Formas de legitimación de acción política intermunicipal entre Bolivia, Chile y Perú (BCP): el caso de la Alianza Estratégica Aymaras Sin Fonteras, Revista Parinas.

Sánchez, Rigoberto (2005).Chile y Bolivia: intereses comunes. La oferta portuaria de la región de Tarapacá al servicio del comercio exterior de Bolivia, Iquique, Ediciones Instituto de Estudios Internacionales, Universidad Arturo Prat.
Sartori, G (1995). La política. lógica y método de las ciencias sociales, México: Fondo de Cultura Económica.

Schmitter, Phillipe, (1989). Idealismo, Integración, Cambio de Régimen en el Cono Sur, Estudios Internacionales, Año XXVI, $\mathrm{N}^{\circ} 117$.

Soldatos P. (1990), "An Explanatory Framework for the Study of Federal States as Foreign Policy Actors», en Michelman, H.J. y P. Soldados, Federalism and International Relations, Oxford, O.U.P.

Szary, Anne-Laure. (1997), Regiones ganadoras y regiones perdedoras en el retorno de la democracia en Chile: poderes locales y desequilibrios territoriales, Santiago, EURE [online], vol. 23, no. 70, pp. 59-78.

Scott, A. J. (1998), Regions and the world economy. The coming shape of global production, competition and political order, Oxford; Oxford University Press.

Tapia Valdés, J. (2003), Paradiplomacia: las relaciones internacionales de los órganos subnacionales de gobierno, en el marco jurídico-institucional de la Integración transfronteriza subregional, Iquique, Universidad Arturo Prat, INTE.

Tapia Valdés, J. (2003), Descentralización, diplomacia y paradiplomacia en la época de la globalización., en Estudios Fronterizos. (1). INTE/Universidad Arturo Prat

Tapia Valdés, J. La Neosubsidiariedad: el principio de subsidiaridad en el proyecto de constitución Europea, 379 Corpus Iuris Regionis, Jurídica Regional y Subregional Andina, Universidad Arturo Prat Iquique, Chile pp. 379-398.

Torrijos, V. (2000), «La diplomacia centrífuga. Preámbulo a una política exterior de las regiones», en Revista Desafíos. Bogotá, Universidad del Rosario.

Vargas, M. (2004), Globalización, desarrollo regional y atomización del Estado Nación. Tesis para optar el título de Magister en Planificación y Administración del Desarrollo Regional, Universidad de los Andes, Bogotá, Colombia Disponible en: www. region.itgo.com. 
Gilberto Aranda et al. • Experiencias paradiplomáticas en la región de Tarapacá...

Wendt, Alexander (1999), Social Theory of International Politics, Cambridge; Cambridge University. Press.

Witker, I. (2004), Mediterraneidad, soberanía y paradiplomacia: tres ejes de discusión teórica para la problemática chilenoboliviana en Revista Política y Estrategia (93). Santiago, Academia Nacional de Estudios Políticos y Estratégicos.
Zamorano Guzmán, Cristián (2007), L'internationalisation d'une region dans le cadre, d'un ètat centraliste et souverainiste : le cas de la region de Tarapaca au Chili. Tesis doctoral, Université Sorbonne NouvelleParis III, Institut des Hautes Etudes de l'Amerique latine, IHEAL. 